\title{
Linking narratives and energy system modelling in transport scenarios: A participatory perspective from Denmark
}

Venturini, Giada; Hansen, Meiken; Andersen, Per Dannemand

\section{Published in:}

Energy Research and Social Science

Link to article, DOI:

10.1016/j.erss.2019.01.019

Publication date:

2019

Document Version

Peer reviewed version

Link back to DTU Orbit

Citation (APA):

Venturini, G., Hansen, M., \& Andersen, P. D. (2019). Linking narratives and energy system modelling in transport scenarios: A participatory perspective from Denmark. Energy Research and Social Science, 52, 204220. https://doi.org/10.1016/j.erss.2019.01.019

\section{General rights}

Copyright and moral rights for the publications made accessible in the public portal are retained by the authors and/or other copyright owners and it is a condition of accessing publications that users recognise and abide by the legal requirements associated with these rights.

- Users may download and print one copy of any publication from the public portal for the purpose of private study or research.

- You may not further distribute the material or use it for any profit-making activity or commercial gain

- You may freely distribute the URL identifying the publication in the public portal 


\section{Linking narratives and energy system modelling in transport scenarios: a participatory perspective from Denmark}

\section{Abstract}

In energy and transport policy research, the creative process of building narrative storylines allows investigating future structures of the system under analysis, thus interpreting causal relations and interdependencies. Quantitative tools instead model the deterministic structure of the system, thus enhancing the validity of input assumptions and presenting long-term implications of policies. However, the process of integrating narratives and modelling remains an intricate phase for deriving robust policy recommendations. The present paper investigates the iterative and participatory application of driving forces in bridging qualitative and quantitative methods in transport scenarios, presenting the case of the Danish transport sector. Stakeholders generate key driving forces and narratives of transport futures as a collective action. Subsequently, a structured prioritization, translation and quantification of the driving forces and qualitative storylines yields the generation of quantitative scenarios in the energy system model TIMES-DK. We discuss the opportunities and challenges of our approach, underlining that the use of multiple driving forces is a critical aspect for the creation of coherent storylines. The communication among actors has a central role in the iterative process for increasing mutual enrichment and validation. The existing gap between modelling results and the future evolution of the transport sector can be overcome by reinforcing a constant dialogue, as to both embrace stakeholders' perspectives, and to secure an impact on transport policy making.

Keywords Socio-technical transition; Driving forces; Collaborative planning; Sustainable transport

\section{$1 \quad$ Introduction}

In the transport sector, a long-lived dependence on fossil fuels with consequent lock-in effects in the infrastructure network have for long determined a slow pace in the transition to renewable sources. According to IEA (2017), the transport sector is today responsible for $21 \%$ of the total greenhouse gases (GHG) emissions globally. Moving towards a more sustainable transport system, while dealing with a continuous growth in global mobility demand, requires large societal changes at all levels, including technological, political and lifestyle changes.

The complexity and uncertainty around the evolution of this interdependent socio-technical system implies that its future configuration cannot be forecasted, but rather shaped, by initiating and supporting discussions among laypersons and politicians. Scenario methodologies are increasingly adopted in the discussion around the future of transport (Banister \& Hickman, 2013), with growing focus and importance being attributed to participatory and inclusive scenario creation exercises (Soria-Lara \& Banister, 2018; Baumann \& White, 2015). The involvement of stakeholders, such as scientists, policy makers and citizens, in the process of scenario planning contributes to securing an impact on policy-making (Volkery \& Ribeiro, 2009), by translating technical solutions into practical and feasible policy recommendations through dialogue and negotiations (Mostashari, 2005).

In this respect, several authors identified an "implementation gap" in transport and energy policy (Cherp et al., 2018; Sovacool, 2014; Banister \& Hickman, 2013). Adopting collaborative and multidisciplinary approaches in scenario development can provide a broader and integrated perspective, thus embracing not 
only techno-economic elements but also considering social and political implications (Li \& Pye, 2018; Moallemi \& Malekpour, 2018; Sovacool, 2014).

The creative process of building qualitative scenarios, i.e. narratives, is explorative and stimulating in nature. It allows investigating future structures in the system under alternative combinations of trends and policies (Turnheim et al., 2015), thus interpreting causal relations and interdependencies (Fontela, 2000). On the other hand, quantitative tools typically model the deterministic structure of the system (Garb et al., 2008), thus having the power to enhance the reliability and validity of input assumptions, and to present cumulative and long-term implications of policies (Papachristos, 2014).

In scenario practice, the dichotomy between explorative and predictive scenarios (Nielsen \& Karlsson, 2007) for long created a divide between respectively scenario writers and modellers (Fontela, 2000). Narrative explorations of futures (explorative scenarios) were hardly integrated into short-term forecasting models (predictive scenarios), due to differences in the theoretical framework of the two perspectives. However, the development of more complex mathematical tools for long-term assessments renovates the need and opportunity to connect the two worlds, qualitative and quantitative (Fortes et al., 2015; Papachristos, 2014; Garb et al., 2008).

A number of scenario studies apply a combination of quantitative and qualitative approaches in the fields of transport (Soria-Lara \& Banister, 2018; Hickman et al., 2012; McDowall, 2014; Varho \& Tapio, 2013; World Energy Council, 2011; TransVisions, 2009), energy (Robertson et al., 2017; Fortes et al., 2015; Mathy et al., 2015; Trutnevyte et al., 2014) and environment (Kok et al., 2011; European Environment Agency, 2007; Nakicenovic et al., 2000).

Across these studies, a common methodological feature is the use of "driving forces" for the creation of consistent scenarios (Fortes et al., 2015; Kok et al., 2011; European Environment Agency, 2007). Driving forces determining future scenarios are hereby intended as an operational tool in the scenario building process (see Section 2), as earlier recognized in Schwartz's seminal work on scenario planning (Schwartz, 1996). Moreover, some foresight exercises explicitly apply the Story and Simulation (SAS) approach (Alcamo, 2008) as an overarching framework for the organization of the scenario planning process (O'Mahony, 2014; Kämäri et al., 2008; European Environment Agency, 2007).

Under this framework, researchers describe the translation and dialogue between narrative storylines and numerical models as an intricate and challenging step (Trutnevyte et al., 2014; Fortes et al., 2015), due to e.g., the difficulty in providing quantitative estimates to highly uncertain drivers (Varho \& Tapio, 2013); presence of implicit information in the qualitative descriptions (Hansen et al., 2016; Fortes et al., 2015); and time-consuming exercises with hard to grasp concepts, as fuzzy set theory (Kok et al., 2015) or multi-criteria analysis (Hickman et al., 2012).

On the other hand, others acknowledge the relevance of maintaining a dialogue between scenarios and models, not just to reproduce the dynamics of each storyline, yet rather to mutually examine and validate the two exercises run in parallel (McDowall, 2014), to highlight differences and similarities between the two points of view (Fortes et al., 2015), and to promote greater transparency around modelling assumptions and uncertainties (Pye et al., 2018). Nonetheless, very few studies strive for rendering and systematically describing the translation methodology in a transparent and generalizable manner, with notable exceptions in other fields than transport (Robertson et al., 2017; Kok et al., 2015). As a result, the process of integrating narratives and modelling remains an intricate phase for deriving robust policy recommendations.

The present study takes inspiration from Fortes et al. (2015), where narrative and quantitative scenarios (modelled in TIMES_PT) were combined to study two alternative pathways for the Portuguese energy system. The authors adopted the general SAS approach and apply the concept of driving forces. However, two possible methodological improvements can be identified from a review of Fortes' study. As driving forces were interpreted and loosely drawn from the storylines in the translation phase, a more systematic approach 
based on a shared and consolidated set of drivers can further the robustness of the scenario exercise. Moreover, as also indicated by the same authors, the study lacked an iterative step, where the modelled scenarios can be revised by stakeholders.

In light of these observations, the present paper aims at investigating the iterative application of driving forces in the participatory process of creating transport scenarios, from the identification of relevant drivers to the formulation of narrative storylines, their translation into quantitative model attributes and the revision of modelled scenarios with stakeholders. We apply a combination of qualitative and quantitative methods to study the case of the Danish transport sector in a participatory setting, attempting at rendering the "softer" steps of the foresight process in a more explicit manner (Garb et al., 2008). The case study reports on the scenario planning process within the COMETS project ${ }^{1}$, which aims at initiating a discussion on the future of the Danish transport system with stakeholders, citizens, and politicians. The project seeks to contribute at identifying and optimizing policies and investments within an integrated energy system model incorporating the transport sector, i.e. TIMES-DK, thus supporting Denmark's 2050 goal of becoming independent of fossil fuels.

The remainder of the paper is structured as follows: Section 2 provides the theoretical framework on the use of driving forces in transport scenario planning; Section 3 describes the methodology applied and the modelling framework; Section 4 presents the results while methodological and transport policy insights are discussed in Section 5. Finally, Section 6 draws the conclusions and elaborate on further work.

\section{Driving forces in transport scenarios}

In scenario literature, driving forces, or simply called drivers, can be generally defined as those trends and patterns, which can influence the outcome of events (Schwartz, 1996). Drivers can be classified in social, technological, economic, political and environmental factors. Furthermore, stakeholders should pay attention to the most uncertain and relevant driving forces when building plausible future scenarios (Alcamo, 2008).

Although standing as a general concept and tool, different interpretations exist for the role of driving forces in scenario creation, i.e. backbone, foundation and building scaffold (van't Klooster \& van Asselt, 2006), encompassing increasing degrees of flexibility in their use. In their more traditional function, driving forces support the definition of the main dimensions, i.e. the guiding axes, along which the scenarios are crafted, as in recent transport and energy scenario studies (Blanco \& Moudon, 2017; Alizadeh et al., 2016; Schuckmann et al., 2012). Other practitioners are experimenting with less strict applications of driving forces (Bryant \& Lempert, 2010; Ramirez \& Wilkinson, 2014), where several of these are combined to define one single region of interest. On the other hand, Wilkinson et al. (2013) argue that driving forces are not the only important set of factors shaping the future, highlighting how micro causes could influence the future as an emergent effect.

Despite the possibly different attributed roles, a common characteristic across foresight exercises is that the determination of the key driving forces becomes functional to the development of scenarios. In many cases, scenarios are built along few dimensions, identified through literature reviews, brainstorming sessions and scenario workshops, as the most relevant forces driving the future changes in the system under analysis. Moreover, even when driving forces are not directly employed in the scenario definition, the collective process of determining the most relevant and uncertain factors serves the purpose of aligning stakeholders and modellers' thinking of the future (Berkhout et al., 2002).

Within the SAS approach, driving forces are central to the communication between narrative storylines and quantitative models (Alcamo, 2008). However, the author himself pinpoints some drawbacks to the method

\footnotetext{
${ }^{1}$ http://www.cometsproject.dk/
} 
of converting the qualitative knowledge in the storylines to numerical model inputs, namely in terms of reproducibility and conversion. The first issue relates to rendering the assumptions and cause-effect relationships behind the storylines in a transparent manner. The second problem undermines the scientific credibility of the scenario analysis, whenever the conversion between the narratives and the model inputs often relies on "best judgment". Moreover, permanent misalignment in the number and level of detail of the driving forces results in incomplete scenarios.

To cope with the lack of transparency and universality of the translation phase, which stands at the core of the integration between the quantitative and qualitative perspectives, a number of studies have addressed the issue from different angles. McDowall (2014) highlights the relevance of establishing a dialogue between the two methods to induce further insights than when using standalone approaches. Fortes et al. (2015) combines quantitative modelling and storylines to assess the differences and similarities between the two perspectives. Robertson et al. (2017) illustrate the strengths of an iterative and mutual calibration. Geels et al. (2016) propose a framework for bridging rational goal-oriented analysis with feasible pathways and emerging options, identified through socio-technical analysis and practice-based action research.

In the transport field in particular, given the environmental threat posed by a slow transition away from fossil fuels coupled with a continuous growth in transport activity, literature envisioning sustainable transport futures has been produced in the recent years. Table 1 summarizes the characteristics of the reviewed literature studies, focusing on the creation and analysis of future transport and energy scenarios. The reader may consult Appendix A, containing further details and classification for the reviewed literature.

According to the adopted methodological approach (Methods and Foresight elements), studies can be grouped into three main sets: the first, and largest, group relies on qualitative and semi-quantitative approaches to scenario development, including review studies, expert consultations and Delphi surveys, as in e.g. European Community (2004) and ERTRAC (2009). A second group focuses mostly only on quantitative methods, e.g. the IEA study (International Energy Agency, 2016b). The last group of studies employs a combination of qualitative and quantitative methods, including an iterative process of stakeholder involvement by integrating expert workshops with quantitative modelling activities, through e.g. the development of meta-models (TransVisions, 2009) and integration of bottom-up scenarios derived from regional workshops (World Energy Council, 2011).

While driving forces are commonly used, their role and application vary across the scenario planning processes. They can constitute the backbone of the scenario creation (European Community, 2004; Tuominen et al., 2014); they are more loosely drawing the foundation of the foresight exercise (ERTRAC, 2009; EA, 2008); or they inform the scenario building process acting as a background study, i.e. "building scaffold" (TransVisions, 2009; World Energy Council, 2011). Across the studies reviewed, the translation of scenario narratives into the quantitative modelling, as well as the role of driving forces in the process, was either not explicitly described, not performed or not sufficiently comprehensive for the full set of scenarios. To this respect, the lack of transparency in the definition of scenarios can undermine the credibility and robustness of the analyses.

Considering the potential role of driving forces in bridging the quantitative and qualitative scenarios, we aim at investigating whether an iterative and participatory approach in the scenario planning process can support the translation from storylines to quantitative modelling inputs, and serve in the dialogue between the two perspectives. 
Table 1. Characterization of studies focusing on the development of transport scenarios. An empty cell under "Driving forces" indicates that they have not been employed in the study. Specification of "Translation" is indicated only for those studies applying a combination of quantitative and qualitative methods.

\begin{tabular}{|c|c|c|c|c|c|}
\hline Project and affiliation & Region & Methods & Foresight elements & Driving forces & Translation \\
\hline $\begin{array}{l}\text { FORESIGHT for TRANSPORT } \\
\text { (European Community, } \\
\text { 2004) }\end{array}$ & EU & Qualitative & $\begin{array}{l}\text { Surveys } \\
\text { Narratives }\end{array}$ & $\begin{array}{l}\text { Multiple } \\
\text { Backbone }\end{array}$ & \\
\hline $\begin{array}{l}\text { Backcasting approach for } \\
\text { sustainable mobility - JRC } \\
\text { (European Commission, } \\
\text { 2008) }\end{array}$ & EU & Qualitative & $\begin{array}{l}\text { Literature review } \\
\text { Backcasting }\end{array}$ & & \\
\hline $\begin{array}{l}\text { Road Transport Scenario } \\
2030+ \\
\text { (ERTRAC, 2009) }\end{array}$ & EU & Qualitative & $\begin{array}{l}\text { Literature review } \\
\text { Workshop } \\
\text { Narratives }\end{array}$ & $\begin{array}{l}\text { Multiple } \\
\text { Foundation }\end{array}$ & \\
\hline $\begin{array}{l}\text { TransVisions, Mobility } \\
\text { scenarios toward } \\
\text { a post-carbon society - } \\
\text { (TransVisions, 2009) }\end{array}$ & EU & $\begin{array}{l}\text { Qualitative + } \\
\text { Quantitative }\end{array}$ & $\begin{array}{l}\text { Workshop } \\
\text { Survey } \\
\text { Narratives } \\
\text { Transport model } \\
\end{array}$ & $\begin{array}{l}\text { Multiple } \\
\text { Building scaffold }\end{array}$ & Through calibration \\
\hline $\begin{array}{l}\text { EU Transport GHG: Routes } \\
\text { to } 2050 \text { ? - European } \\
\text { Commission } \\
\text { (Skinner et al., 2010) }\end{array}$ & EU & $\begin{array}{l}\text { Qualitative + } \\
\text { Quantitative }\end{array}$ & $\begin{array}{l}\text { Literature review } \\
\text { Transport model }\end{array}$ & & Not performed \\
\hline $\begin{array}{l}\text { Global Transport } \\
\text { Scenarios } 2050 \\
\text { (World Energy Council, } \\
\text { 2011) }\end{array}$ & Global & $\begin{array}{l}\text { Qualitative + } \\
\text { Quantitative }\end{array}$ & $\begin{array}{l}\text { Workshop } \\
\text { Narratives } \\
\text { Energy model }\end{array}$ & $\begin{array}{l}\text { Multiple } \\
\text { Building scaffold }\end{array}$ & $\begin{array}{l}\text { Not performed/ } \\
\text { Not described }\end{array}$ \\
\hline $\begin{array}{l}\text { TOP-NEST - VTT } \\
\text { (Tuominen et al., 2014) }\end{array}$ & $\begin{array}{l}\text { Nordic } \\
\text { countries }\end{array}$ & Qualitative & $\begin{array}{l}\text { Workshop } \\
\text { Value chains } \\
\text { Narratives }\end{array}$ & $\begin{array}{l}\text { Two-axes } \\
\text { Backbone }\end{array}$ & \\
\hline $\begin{array}{l}\text { Nordic Energy Technology } \\
\text { Perspectives } 2016 \\
\text { (International Energy } \\
\text { Agency, 2016) }\end{array}$ & $\begin{array}{l}\text { Nordic } \\
\text { countries }\end{array}$ & Quantitative & $\begin{array}{l}\text { Energy and transport } \\
\text { model }\end{array}$ & & \\
\hline $\begin{array}{l}\text { Danish Greenhouse Gas } \\
\text { Reduction Scenarios for } \\
2020 \\
\text { and } 2050 \\
(E A, 2008)\end{array}$ & Denmark & $\begin{array}{l}\text { Qualitative + } \\
\text { Quantitative }\end{array}$ & $\begin{array}{l}\text { Workshop } \\
\text { Energy model }\end{array}$ & $\begin{array}{l}\text { Multiple } \\
\text { Foundation }\end{array}$ & Not performed \\
\hline $\begin{array}{l}\text { IDA Climate Plan } 2050 \\
\text { (IDA, 2009) }\end{array}$ & Denmark & $\begin{array}{l}\text { Qualitative + } \\
\text { Quantitative }\end{array}$ & $\begin{array}{l}\text { Workshop } \\
\text { Energy model }\end{array}$ & & $\begin{array}{l}\text { Not performed/ } \\
\text { Not described }\end{array}$ \\
\hline $\begin{array}{l}\text { Coherent Energy and } \\
\text { Environmental System } \\
\text { Analysis (CEESA) - Aalborg } \\
\text { University } \\
\text { (Lund et al., 2011) }\end{array}$ & Denmark & Quantitative & Energy model & & \\
\hline $\begin{array}{l}\text { Danish Transport without } \\
\text { coal and oil - how? } \\
\text { (Teknologirådet, 2012) }\end{array}$ & Denmark & $\begin{array}{l}\text { Qualitative + } \\
\text { Quantitative }\end{array}$ & $\begin{array}{l}\text { Expert consultation } \\
\text { Energy model }\end{array}$ & & Not performed \\
\hline $\begin{array}{l}\text { Fossil-free Road Transport } \\
2050 \\
\text { (Dansk Energi, 2013) }\end{array}$ & Denmark & Qualitative & $\begin{array}{l}\text { Expert panels } \\
\text { Backcasting }\end{array}$ & & \\
\hline $\begin{array}{l}\text { Future energy scenarios } \\
\text { towards 2020, } 2035 \text { and } \\
2050 \\
\text { (Danish Energy Agency, } \\
2014 b \text { ) }\end{array}$ & Denmark & Quantitative & Energy model & & \\
\hline $\begin{array}{l}\text { Green Roadmap } 2030 \\
\text { (EA, 2015) }\end{array}$ & Denmark & Quantitative & $\begin{array}{l}\text { Workshop } \\
\text { Energy model } \\
\text { Transport model }\end{array}$ & & \\
\hline
\end{tabular}




\section{3}

\section{Methodology}

\subsection{The case of the Danish transport sector}

Denmark's ambitious energy and climate policy has in the last decade driven towards the integration of renewable energy and the gradual phase-out of fossil fuels, especially in the heat and power sector. A comparison made by the World Energy Council ranking 125 countries' energy performance shows that Denmark is on the top of the index (World Energy Council, 2016). Since 2011, the Danish policy has been aiming towards an energy system independent of fossil fuels by 2050 (Danish Energy Agency, 2015). However, the transport sector is currently dominated by the use of fossil fuels (Sovacool \& Blyth, 2015), as is for most countries globally, thus hindering a complete transition to a low-carbon society by 2050 (Danish Energy Agency, 2015). The COMETS project grew out of this political landscape. One overall goal of the project is to investigate the future evolution of the transport sector in Denmark, by e.g., studying whether an already favourable configuration of the Danish energy system, with a large share of renewable-based electricity, offers the opportunity for a further integration of the transport sector (Mathiesen et al., 2015). The relevance of the case study primarily stems from the availability of an integrated energy and transport system model for scenario analysis i.e., TIMES-DK, and from a widespread and traditional culture of stakeholder participation i.e., policy makers, agencies, research institutions, into the discussion of societal issues of relevance for the country.

\subsection{The methodological framework for scenario development}

For this case study, the SAS framework (Alcamo, 2008) was enlarged to accommodate greater emphasis on the communication between the storylines and the model. With the aim of investigating the iterative and participatory role of driving forces in the planning process of transport scenarios, the core of our analysis covers: a) foresighting (generation of key drivers and narrative storylines), b) translation (quantification of the driving forces into modelled scenarios), and c) revision (Figure 1). Within foresighting, the identification of driving forces, narratives development and their revision were executed as two consecutive workshops, grounding on the participatory scenario work of the PRELUDE project (European Environment Agency, 2007). The PRELUDE project (PRospective environmental analysis of Land-Use Development in Europe) was initiated by the European Environment Agency, with the main objective of building future scenarios of land-use in Europe. In particular, "with the PRELUDE initiative, the EEA decided to embark on a truly participative scenario building process. In order to achieve this, the project team carefully selected a group of stakeholders from across Europe, representing a wide variety of interests and perspectives" (European Environment Agency, 2007 p. 9). Building on the PRELUDE project, the first workshop (WS1) involved the scenario team (Section 3.2.1), and the second workshop (WS2) included the scenario panel (Section 3.2.2). The two workshops, both facilitated by the third author, were video-recorded and later transcribed and coded in the software Atlas.ti ${ }^{2}$ for data collection and analysis.

The scenario team was composed of the project scientific group, with fields of expertise ranging from engineering, energy modelling and transport to social science applied to transitions in the energy and transport system. The scenario team comprised 12 scientists ( 10 males and 2 females), with age varying from 25 to 65 years. The purposive selection of the stakeholders forming the scenario panel was performed with the aim of including representatives from a variety of public and private organizations in the energy and transport domain in Denmark. Another important objective was to include stakeholders with a wide range

\footnotetext{
${ }^{2}$ Atlas.ti is a qualitative data analysis software. It can be used for qualitative analysis of documents, graphical, audio and video data, including various options for arranging and managing data and code (https://atlasti.com/)
} 
of perspectives on issues related to energy and transport in Denmark. As a result of the selection process and the availability of stakeholders, the scenario panel included a total of 12 professionals from the energy and transport sectors, of whom three were female, with age ranging from 30 to 65 years. The scenario panel represented different interests in the transport and energy sectors in Denmark, comprising stakeholders with varying expertise and knowledge. The scenario panel included participants affiliated to institutions covering state organizations (e.g. the Danish Road Directorate), interest organizations (e.g. Federation of Danish Motorists, Danish Cyclists' Federation), public transport companies, agencies and independent environmental organizations.

The Post-Foresight steps, i.e. Implementation and Learning, are not included in this paper, as the main focus is herein set on the integration of modelling and storylines. The learnings for transport and energy policymaking will be included in a follow-up paper.
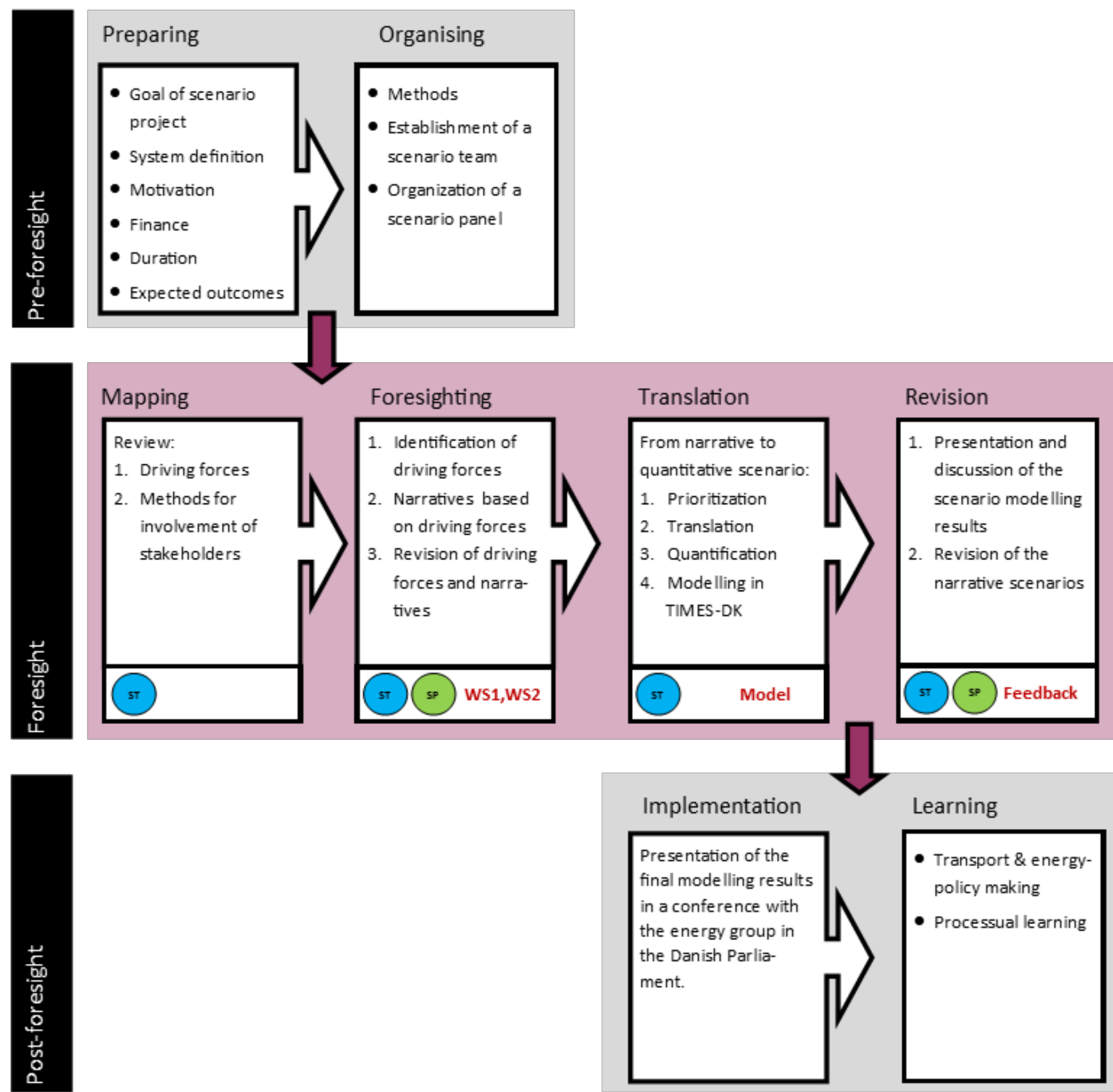

Figure 1. Methodological set-up for this study, with focus on the central phase "Foresight". Legend: ST=Scenario Team, SP=Scenario Panel, WS=Workshop [Figure adapted from Andersen \& Rasmussen, 2012]. 


\subsubsection{Foresighting: qualitative scenarios}

The adopted approach for the description of transport scenarios aims at capturing more than two dimensions (Volkery et al., 2008). The use of multiple driving forces in facts allows for more comprehensive qualitative scenarios (Ramirez \& Wilkinson, 2014), in turn supporting a more transparent translation and quantification of the qualitative inputs into quantitative model attributes (Sections 3.2.3 and 3.2.4).

During a first workshop (WS1), the scenario team brainstormed on parameters and driving forces affecting the Danish transport sector, in the context of reaching a 100\% renewable energy system in 2050 . This process was facilitated by an initial presentation of driving forces and game changers, which may affect the future transport system. These included societal factors (e.g. urbanisation and sharing economy), technological factors (e.g. autonomous vehicles and electric vehicles (EV)), economic factors (e.g. GDP growth and interest rates) and political factors (e.g. environmental targets). Additional drivers highlighted by the scenario team covered consumer preferences and behaviour, urban planning and transport infrastructure. The parameters identified at this stage formed a list of detailed factors relevant to consider in relation to the future energy and transport system in Denmark, later to be grouped into key driving forces.

Subsequently, participants reflected individually on the impact and uncertainty of the identified parameters in relation to the Danish energy system. Impact relates to the expected importance of the parameter on the whole energy system (e.g. relevance of electric vehicles for the decarbonization of the transport sector). Uncertainty is associated with either the expected large variation in the effect of a certain parameter on the energy system (e.g. effect of autonomous vehicles on transport demand) or with the inherent variability and fluctuation of a parameter (e.g. future fuel prices). The qualitative assessment of impact and uncertainty was performed through the assignment of green (for impact) and red (for uncertainty) marks from a set of 16 marks ( 8 green and 8 red), available to each participant and to be shared among all parameters considered.

The number of marks available to each participant was chosen to be lower than the number of parameters to be qualitatively assessed. Considering that around 20 parameters were to be evaluated in the first workshop, each participant could use only 16 marks, thus reflecting on the parameters that he/she considered the most relevant and uncertain, without the possibility of assigning marks to all available parameters. To maintain consistency between the two workshops, the same amount of marks was later provided also to the scenario panel.

The reason for employing this evaluation step was to facilitate a discussion among the participants and determine the most impacting and uncertain parameters within each key driving force. We chose to facilitate the discussion through this generic step (assigning red and green marks to parameters), as applied in previous scenario planning exercises (Andersen et al., 2014). Following the voting step, the participants justified their choices in a roundtable discussion. As highlighted by Nowack et al. (2011), the involvement of experts and stakeholders in scenario planning exercises is important to initiate a prioritization of drivers.

Afterwards, the scenario team grouped the parameters into overall categories i.e., driving forces. During this stage, discussions allowed iteratively to reach an agreement on the number and name of the key driving forces, as well as the assignment of the individual parameters to the key driving forces. Furthermore, when grouping the parameters into driving forces, the concept of "influence chains" was adopted. Influence chains (European Environment Agency, 2007; Tuominen et al., 2014) allow linking the different parameters together by considering cause-effect relationships between them and other system implications.

As the last stage of the process, participants drafted scenario storylines by selecting different combinations of the created driving forces, each one described on a 3-level qualitative scale (low, medium and high). This scenario creation phase was organized as a brainstorming session for both workshops, with participants working in groups and discussing possible developments for each driving force. Initially, the groups did not specify a common scale for the three levels. After presenting the scenario narratives in plenum, participants agreed to the need of a common scale, as differences arose in the interpretation of the driving forces. 


\subsubsection{Foresighting: revision of driving forces and narratives}

In a second workshop with the scenario panel (WS2), the foresight exercise followed the same methodology as for the scenario team performed in WS1, with identification of a list of parameters, assignment of the most influencing and uncertain factors, grouping in key driving forces and creation of scenario narratives. As a differentiating feature with respect to the first workshop, the scenario panel focused on the revision of the driving factors defined previously, instead of defining them from scratch. Furthermore, the scenario panel firstly reviewed the scenario outlines elaborated by the scenario team, and secondly created new scenarios by defining new combinations of key driving forces. This modified workshop structure was an intended decision, grounded on two main reasons: the necessity of establishing a common starting point and avoid otherwise inevitable and not relevant divergences in such a heterogeneous stakeholder group, as well as the limited time available by the participants i.e., a working day.

\subsubsection{Translation: quantification of driving forces}

In line with the adopted SAS approach, the qualitative information from the workshops was translated into quantitative model inputs, following a series of steps: (i) peer-reviewed prioritization of parameters within the scenario team, (ii) translation of the most critical parameters from qualitative descriptions into model attributes, (iii) determination of the quantitative levels for each model attribute (Section 3.2.4).

The peer-reviewed prioritization step (i) within the scenario team focused on determining the most critical parameters within each key driving force to include in the model set-up, in order to represent the future transport scenarios. The decision criteria included: the possibility to capture the parameter in the chosen model under the envisioned model development, the impact of the parameter on the transport and energy system, and the relevance of the parameter in the context of a $100 \%$ renewable energy scenario.

The following step (ii) involves the translation of the qualitative parameter descriptions into usable model attributes. The scientific modelling team performed the translation process, combining knowledge on the capabilities and structure of the energy system model adopted within this study, TIMES-DK (see Section 3.2.4), with the parameters described within scenario narratives. As for the prioritization step, also this phase underwent peer-review within the scenario team.

During this stage, some parameters could not be translated into model attributes due to the difficulty of assessing their impact on the system or due to the high level of detail, relatively to the model capabilities and scope. As an example, work flexibility relates to flexibility at the workplace, in terms of flexible working hours, possibility of teleworking and substitution of physical with virtual meetings, all of which could influence the future transport system. The effects could include reduced transport demand for commuting and decreased congestion rate at rush hours. Nonetheless, the relationship between work flexibility and transport demand is certainly not linear. Moreover, the implementation of such relationship in an energy system model (see Section 3.2.4) requires the determination of relation coefficients for variables like e.g., "exit hour from work" or "distance work-home". However, these elements are over-detailed to be described in the modelling framework used for this study.

\subsubsection{Translation: modelling of the quantified scenarios}

Following the translation, the quantification of impact levels included the investigation of the historical trends, current state and future planned development for each parameter. To maintain consistency along the quantification process, the three development levels share the same basic assumptions: for each parameter to be quantified, the low level is determined through extrapolation of the historical trend; the high level scenario corresponds to the most optimistic development; the medium level, whenever used, assumes an evolution in between the low and high levels. Although this common framework has been 
adopted along the whole quantification process, all assumptions have been collected for future discussion and validation with stakeholders during the follow-up feedback sessions on modelling results (Section 4.6). The chosen modelling tool TIMES-DK is a bottom-up least-cost optimization energy model, covering the Danish energy system geographically aggregated in two regions, with technological and economic projections until 2050 (for a complete overview of the model, the reader may refer to Balyk et al. (2019)). Figure 2 illustrates the model structure with commodities and processes being the main entities of the system. On the supply side, commodities can be either imported, exported or domestically produced (e.g. coal and woodchips). Conversion technologies (e.g. combined heat and power plants) transform the different commodity inputs into usable energy services (e.g. heat and electricity), which need to satisfy the annual end-use sector demands (i.e. residential, industry and transport). Model inputs include techno-economic characteristics of conversion processes (i.e. costs, efficiencies and $\mathrm{CO}_{2}$ emission factors), end-use energy demands (e.g. annual passenger travel demand) and prices of imported fuels (e.g. electricity trade with neighbouring regions). TIMES-DK simultaneously optimizes operation and investments across the complete energy system over the whole modelling horizon, as to satisfy the end-use demands at the minimum cost. In particular, the transport sector includes inland (private car, bus, coach, rail, 2-wheeler, bike and walk), maritime and air modes, both passenger and freight. Within the inland passenger transport, TIMES-DK determines modal shares endogenously: modal competition is based on the levelised costs of the modes, speed and infrastructure requirements (Tattini et al., 2018). As we focus on the translation of qualitative narratives into quantitative scenarios, the specifics of model implementation will not be part of the discussion. However, few examples are made on the quantification of model attributes, to afford a better understanding of the translation process (Section 4).

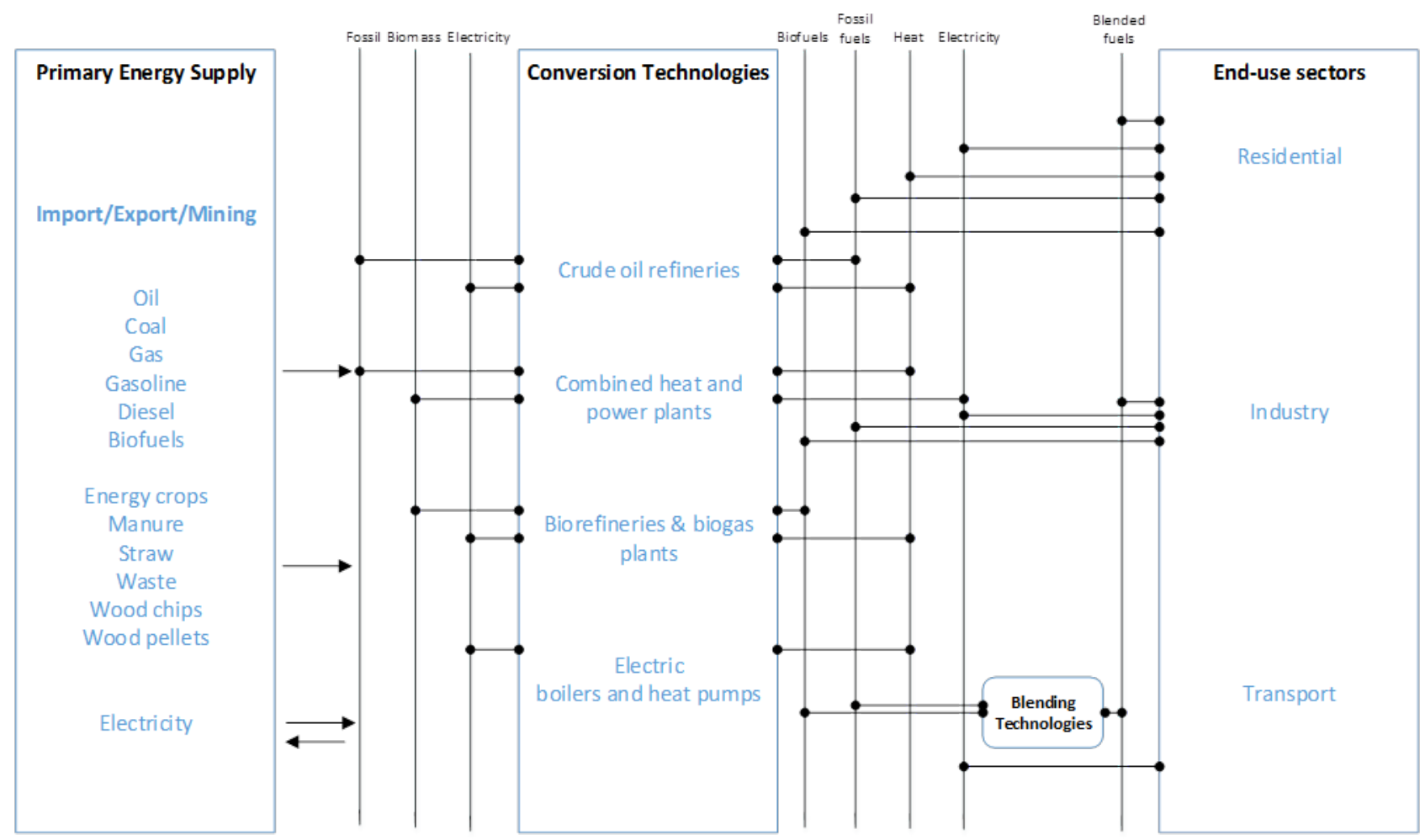

Figure 2. Schematic representation of the energy system model TIMES-DK, including supply, conversion and end-use sectors. Horizontal lines represent the flow of commodities within the system (e.g. from supply to conversion), while vertical lines aggregate the commodities in sets (e.g. fossil, biomass, electricity). 


\subsubsection{Revision}

The integration of quantitative and qualitative methods can advance scenario creation because it combines different perspectives on a certain field (Fortes et al., 2015), i.e. the Danish transport sector in our case. Moreover, as long as models incorporate aspects of reality only as fixed inputs (Garb et al., 2008), they cannot be trusted to provide relevant and robust policy recommendations. Therefore, it is of uttermost importance to integrate the knowledge achieved through the quantified scenarios with views from those same stakeholders who contributed in building the qualitative visions of the future. At the same time, this process allows for a participative creation of ideas about the future, in turn enabling the engaged stakeholders to take stronger responsibilities in the decision-making process (Berkhout et al., 2002).

In the revision phase, the quantified scenarios were thus reported back to members of the scenario panel, through individual feedback sessions. The entire group of stakeholders was invited for revision feedback sessions with the first and second author, with seven stakeholders eventually participating. The revision phase was organized in a feedback session format, where the stakeholders were presented with: a) a summary of the previous workshop with the scenario panel, i.e. the narrative scenarios (Section 4.2); b) the translation of driving forces and parameters into model attributes (Section 4.3); c) the quantification of relevant parameters (Section 4.4); and d) the modelling results for two scenarios. Out of seven scenarios created, two were modelled and discussed with the stakeholders, with the aim of clarifying whether the quantified driving forces and modelled scenarios could be interesting and relevant to investigate further. Based on this, a discussion followed, in which stakeholders addressed several issues, including the interpretation of qualitative descriptions into model attributes, the quantification of parameters, additional technologies or parameters to be considered, the specific scenario results and general comments on the scenario storylines.

\section{$4 \quad$ Results and discussion}

\subsection{Generation of driving forces}

The brainstorming sessions among the scenario team (in WS1) and the scenario panel (in WS2) resulted in a wide range of driving forces. Table 2 presents the resulting parameters, their evaluation in relation to impact and uncertainty, and their grouping into driving forces as performed by the scenario team and scenario panel. The number of green and red dots reflects the number of marks assigned to each parameter by workshop participants overall.

Since the scenario panel had added a number of parameters in the second workshop (marked with * in Table 2), not all parameters were evaluated by the scenario team. The clustering of parameters into "influence chains" to determine the key driving forces was initially performed by the scenario team during WS1, with additional parameters introduced by the scenario panel during WS2. Seven key driving forces, each embracing detailed parameters, emerged from the two workshops: Infrastructure, Technology, Policy and Regulation, Behaviour, Demography, Macro Economy and Urban Planning. The latter had low influence in the determination of scenarios, hence will not be considered hereafter. 
Table 2. Identification of the most impacting and uncertain parameters within each key driving force. The number of dots reflects the actual number of dots placed by the members of the scenario team and the scenario panel during the two workshops.

\begin{tabular}{|c|c|c|c|c|c|}
\hline Driving forces & Parameters & Scenario team & & Scenario panel & \\
\hline & & Impact & Uncertainty & Impact & Uncertainty \\
\hline & Infrastructure & $\bullet \bullet \bullet$ & $\bullet$ & $\bullet \bullet \bullet \bullet \bullet \bullet$ & $\bullet \bullet$ \\
\hline \multirow[t]{6}{*}{ Infrastructure } & Accessibility of public transportation & $\bullet \bullet \bullet \bullet \bullet \bullet$ & $\bullet \bullet$ & $\bullet$ & \\
\hline & Biking and parking at train stations* & & & & \\
\hline & Taxation & $\bullet \bullet \bullet$ & $\bullet$ & $\bullet \bullet \bullet \bullet \bullet \bullet \bullet \bullet \bullet \bullet$ & $\bullet \bullet \bullet \bullet \bullet \bullet$ \\
\hline & Local air pollution & $\bullet \bullet \bullet \bullet$ & $\bullet \bullet$ & & \\
\hline & Personal targets & $\bullet \bullet \bullet$ & $\bullet \bullet \bullet$ & & \\
\hline & $\mathrm{CO}_{2}$ targets & $\bullet \bullet$ & $\bullet$ & $\bullet \bullet \bullet \bullet$ & \\
\hline \multirow[t]{7}{*}{ Policy \& Regulation } & Change of tax system* & & & $\bullet \bullet$ & $\bullet \bullet$ \\
\hline & Climate change urgency* & & & & $\bullet \bullet \bullet \bullet \bullet \bullet$ \\
\hline & Tax revenue* & & & & - \\
\hline & Congestion* & & & - & $\bullet$ \\
\hline & Green cities (pollution)* & & & $\cdot$ & $\cdot$ \\
\hline & Urbanisation & $\bullet \bullet \bullet \bullet \bullet \bullet \bullet$ & $\bullet$ & $\bullet \bullet \bullet \bullet \bullet \bullet \bullet$ & $\bullet \bullet \bullet$ \\
\hline & Population density & $\bullet \bullet \bullet$ & - & $\bullet \bullet$ & \\
\hline \multirow[t]{4}{*}{ Demography } & Aging & & $\bullet \bullet$ & & $\bullet \bullet$ \\
\hline & Family patterns* & & & - & $\bullet \bullet$ \\
\hline & Urbanization - self-driving cars effect* & & & & \\
\hline & Economy & $\bullet$ & $\bullet \bullet \bullet \bullet \bullet$ & $\bullet \bullet \bullet \bullet \bullet \bullet \bullet \bullet \bullet \bullet$ & $\bullet \bullet \bullet \bullet \bullet \bullet \bullet$ \\
\hline \multirow{7}{*}{ Macro Economy } & Freight demand & $\bullet$ & $\bullet \bullet \bullet \bullet$ & & \\
\hline & Energy prices & $\bullet$ & $\bullet \bullet \bullet \bullet$ & $\bullet \bullet \bullet \bullet \bullet \bullet \bullet$ & $\bullet \bullet \bullet \bullet \bullet \bullet \bullet \bullet$ \\
\hline & Car manufacturer business models* & & & & \\
\hline & Tourism & $\bullet$ & $\bullet \bullet \bullet \bullet$ & & $\bullet \bullet \bullet$ \\
\hline & Life style changes & $\bullet \bullet \bullet \bullet \bullet \bullet \bullet$ & $\bullet \bullet \bullet \bullet \bullet \bullet \bullet \bullet \bullet \bullet$ & $\bullet \bullet \bullet$ & $\bullet \bullet \bullet$ \\
\hline & Green behaviour & $\bullet \bullet$ & $\bullet \bullet \bullet \bullet \bullet$ & & \\
\hline & Work flexibility & - & $\bullet \bullet \bullet \bullet \bullet \bullet \bullet \bullet$ & $\bullet$ & $\bullet$ \\
\hline \multirow[t]{9}{*}{ Behaviour } & Sharing economy & $\bullet \bullet \bullet$ & $\bullet \bullet \bullet \bullet \bullet \bullet \bullet$ & & $\bullet \bullet \bullet \bullet \bullet \bullet \bullet$ \\
\hline & Opening hours of institutions * & & & - & \\
\hline & E-trading* & & & & \\
\hline & Basic feeling of freedom* & & & & \\
\hline & Free time* & & & & \\
\hline & Autonomous vehicles & $\bullet \bullet \bullet \bullet \bullet \bullet$ & $\bullet \bullet \bullet \bullet \bullet \bullet \bullet \bullet \bullet \bullet$ & $\bullet \bullet$ & $\bullet \bullet \bullet$ \\
\hline & Electric transport & $\bullet \bullet \bullet$ & $\bullet \bullet$ & $\bullet \bullet \bullet \bullet \bullet \bullet \bullet \bullet$ & • \\
\hline & Cost of vehicles & $\bullet \bullet \bullet \bullet \bullet$ & $\bullet \bullet$ & $\bullet \bullet \bullet$ & $\bullet \bullet$ \\
\hline & Travelplan - total app for all modes* & & & - & \\
\hline \multirow[t]{5}{*}{ Technology } & $\begin{array}{l}\text { Hydrogen and gas vehicles, electric* } \\
\text { bikes }\end{array}$ & & & $\bullet$ & $\bullet$ \\
\hline & Biofuels potential* & & & - & $\bullet \bullet$ \\
\hline & Intelligent road, inductive charging* & & & & \\
\hline & 3D print* & & & & $\bullet$ \\
\hline & Drone transport* & & & & $\bullet \bullet$ \\
\hline \multirow{2}{*}{ Urban planning } & Behaviour/demography* & & & $\bullet \bullet \bullet \bullet$ & $\bullet \bullet \bullet \bullet \bullet$ \\
\hline & New urbanisation * & & & & \\
\hline
\end{tabular}

Note: *additional parameters added by the scenario panel.

The most relevant points highlighted by the scenario panel and the scenario team during the generation and evaluation of drivers are hereby reported.

Infrastructure and Technology: Transport infrastructure, with particular reference to EVs and e-bikes infrastructure, was considered important for enabling a stronger technological shift in the private passenger sector, as highlighted also in Tuominen et al. (2014) and European Commission (2008). 
Investments in bike lanes were deemed of minor importance instead by the scenario panel, considering the current and projected future transport work delivered by bikes on the total of all modes. On the other hand, intelligent roads, e-highways and inductive charging should be considered as future development options within freight transport. Among technological factors, biofuels were added to the relevant parameters as they could play a major role in the future freight transport.

Behaviour: Car sharing was discussed among the stakeholders, raising contrasting opinions about the likelihood of expansion and flexibility of this system, decreasing private car ownership and the potential effect of increasing mobility. Sharing economy might influence freight transport on a larger scale through the increasing phenomenon of e-commerce. Moreover, the concept of Maas (Mobility-as-a-Service) was remarked, outlining the possibility of developing mobile travel applications optimizing trips in terms of time, cost and sustainability. Accessibility and user-friendly public transport (e.g. park and ride options) could boost the use of this transport mode. Further, emerging lifestyle changes and higher environmental awareness, in combination with virtual meetings and the advent of MaaS, may affect the selection of vehicles and the use of more sustainable forms of transport. Additionally, imitation effects may play a role in the choice of transport modes. The parameter flexible work hours was seen as a potential factor for avoiding the rush hours, thus improving road capacity and minimizing travelling times.

Policy and Regulation: Stakeholders stressed on the dependency of the Danish state budget on registration taxes from private vehicles, thus challenging dramatic and rapid modifications of the taxation schemes. At the same time, as consumer "green" behaviour alone may be an insufficient driver for transitioning to a more sustainable transport system, incentives realized through subsidies and regulations should be pursued.

Demography: In line with most of the studies reviewed (Section 2), demographic parameters as e.g., age distribution and population density in the different geographical areas were mentioned as relevant factors in relation to the accessibility to public transport, and thus the potential of modal shift. Consistently with some of the measures identified in Teknologirådet (2012), several stakeholders highlighted the strong interdependencies between the factors demography, consumer behaviour and urban planning. For instance, the size of cities and distribution of the different living spaces (residential, workplace and commercial activities) could be optimized to guarantee the desired transport activity and choice of mode.

Grunwald (2011) pinpoints the existence of a diversity of futures in the energy field. The evaluation of the driving forces by two groups involved in our foresight exercise (Table 2) effectively reflects these diversified views on what the future has in store. Both groups evaluated Infrastructure to be of high relevance. However, within this key driving force, the scenario team focused on parameters related to public transport and bikes, i.e. accessibility of public transportation, while the scenario panel criticized the lack of focus on drivers with greater potential, impacting freight transport. Additionally, stemming from the closer link to policy makers within the scenario panel, taxation and change of tax system were rated to be of higher relevance and uncertainty by the scenario panel than the scenario team. Regarding the key driving force Behaviour, the scenario team assigned higher uncertainty level to several parameters, thus highlighting the unpredictable potential role of consumers in shaping the future transport sector. Similarly, the penetration of technologies such as autonomous vehicles may have disruptive consequences on the system, either increasing or diminishing the total transport demand (Wadud et al., 2016). Demography and Macro Economy affect the broader economic and social system, beyond the sole transport and energy sectors. Therefore, the two drivers are only partially considered in future scenario descriptions. 


\subsection{Creation of narrative scenarios}

After identifying the key determinants of the transport futures (O'Neill et al., 2017), i.e. driving forces, the scenario team created a set of five scenarios, by selecting different combinations of the key driving forces, each one described on a 3-level qualitative scale. The adopted scale is common practice across energy scenario studies (Li \& Strachan, 2016; Mathy et al., 2015). For an overview of all the scenario narratives ("High-tech high-reg", "Urban Hippie", "Urban Electrification", "Green Individuals Alone", "Policy and Consumer Driven"), the reader may consult Appendix B.

During the second workshop, the stakeholders developed two more scenarios, as presented in Table 3: "No Leadership - Market delivers" and "Last-minute Action 2050". In this case, the participants were asked to either create their own scenarios or to adjust the scenarios already created by the scenario team.

Semi-structured descriptions in bullet-point form accompanied each scenario. In the narratives, not all the parameters within each key driving force could be described, due to time constraints. Therefore, the translation of narratives into quantitative parameters is subject to a certain level of uncertainty due to unclear or missing qualitative descriptions (Fortes et al., 2015). One important aspect when creating scenarios is to maintain internal consistency (Schweizer \& Kriegler, 2012). Hence, once deciding upon the levels of the 3-level scale for each driving force, participants forcibly reflect on the cross-impacts of the key drivers within the transport system. This process allows for the development of coherent scenarios. For example, in the scenario "Urban Hippie" and "Green Individuals Alone", the presence of a high level of behavioural change in combination with a low technological and infrastructure development, or scarce policy support, needs to be carefully clarified during the elaboration of the narratives. Furthermore, stakeholders themselves highlighted the need for a common understanding and agreement on the description of the key driving forces and the qualitative scale on which they are evaluated.

Table 3. Narrative storylines for two selected scenarios.

\section{No Leadership - Market delivers}

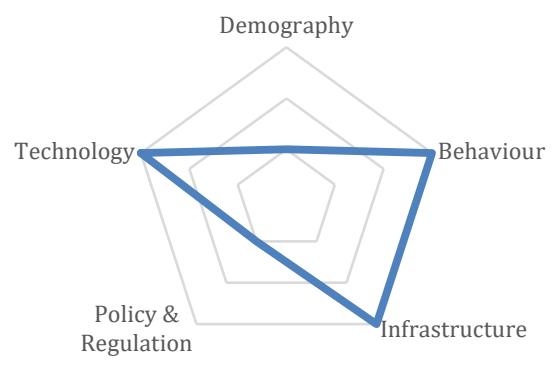

Last minute Action 2050
There will be little political leadership both at local and national level, towards reaching the $100 \%$ renewable transport system in Denmark. Similarly, also urban planning will not be in line to reach the goal. We will see great technological development, in the power generation, storage technologies and production of biofuels. High oil prices will be an important driver for technological development. This will be coupled with high environmental awareness among the consumers, which will be willing to purchase and use new green technologies for transport, both battery electric vehicles and other low-carbon options (e.g. biofuels).

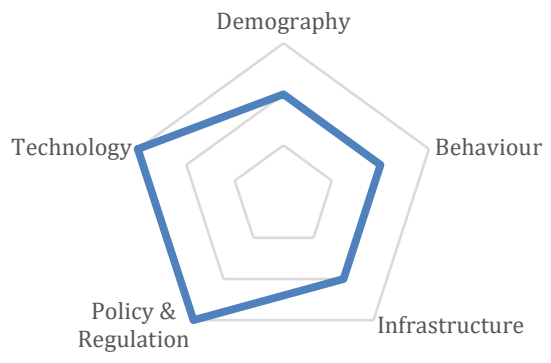

The path towards a more sustainable transport sector is completely relying on the level of technological development and people's behaviour towards the year 2030. After 2030, the environmental goals have failed. Denmark is forced to live up to the renewable energy targets set internationally. To comply with this, a late, yet strong, political response is initiated. Here strict regulations will force consumers to purchase and use more electric vehicles. Therefore, technology and behaviour alone could not drive the transition in the transport system up to 2050 , if not supported by ambitious political actions. 


\subsection{Translation of narrative scenarios}

Since the narrative scenarios were based on the levels assigned to the key driving forces, mainly these latter functioned as guide in the translation and quantification phase. However, given the scope of the energy system model, not all the parameters could be quantified and modelled. We encounter two main sets of challenges: as Trutnevyte et al. (2014) point out, the translated parameters will be a narrower representation of the qualitative storyline, which is rich in detail; furthermore, narrative descriptions often implicitly assume some framework conditions, which cannot thus be rendered explicitly in the quantitative scenarios (Fortes et al., 2015).

Moreover, some parameters could be considered less impacting on the future energy and transport sectors. We therefore firstly prioritized the parameters by taking into account the uncertainty and relevance impacts assigned by the scenario team and the scenario panel, as in Table 2. The priority levels high, medium and low in Table 4 define the overall importance of the parameters in the scenario translation and quantification process.

Considering the key driving force Infrastructure (Table 4), the parameter charging stations for electric vehicles has been given high priority when considering that infrastructure was deemed relevant by both scenario team and scenario panel. On the other hand, biking and parking at train stations was a parameter introduced during the second workshop, but was not considered an important aspect. Therefore, it was assigned low priority. A similar reasoning is behind the prioritization of all other parameters: for example, the high priority given to adoption of electrical transport follows from the high relevance assigned in the workshops, while the less impacting drone transport has been given low priority. However, there are few exceptions stemming from the limitations of the model (Geels et al., 2016): while taxation has been regarded as a key issue among the scenario panel (Table 2), it has been assigned medium priority, given the limited model capabilities in capturing the effects of tax changes on the macroeconomic system. Similarly, lifestyle changes have been recognized as a relevant parameter, especially by the scenario team. However, the relationship between changes in travellers' lifestyle and transport use and demand cannot be comprehensively internalized in the current energy system model, thus only exogenous assumptions on future transport demand and mode shares can be used as model input. Table 4 summarizes the prioritization choice and the translation into model attributes for a set of selected parameters.

Table 4. Prioritization and translation of selected qualitative parameters into model attributes. The qualitative parameter descriptions herein reported represent enlarged definitions of the parameters names reported in Table 2. $H=$ High, $M=$ Medium, $L=L o w$.

\begin{tabular}{|c|c|c|}
\hline Parameter - Qualitative description & Priority & Model implementation - Quantitative input \\
\hline \multicolumn{3}{|l|}{ Infrastructure } \\
\hline $\begin{array}{l}\text { Charging stations: coverage level of charging stations for } \\
\text { electric vehicles }\end{array}$ & $\mathrm{H}$ & $\begin{array}{l}\text { Incorporate and adjust cost and stock of charging infrastructure } \\
\text { for electric vehicles }\end{array}$ \\
\hline $\begin{array}{l}\text { Train speed: increased number of high-speed trains in the } \\
\text { future }\end{array}$ & M & $\begin{array}{l}\text { Train speed to be modified by increasing occupancy factor and/or } \\
\text { decreasing travel time for long distance demands }\end{array}$ \\
\hline Accessibility of public transport & M & $\begin{array}{l}\text { Reduce the time-cost of the public transport mode to simulate a } \\
\text { decrease in the waiting time }\end{array}$ \\
\hline $\begin{array}{l}\text { Biking and parking at train stations: availability of bike } \\
\text { docks at train stations }\end{array}$ & $\mathrm{L}$ & \\
\hline \multicolumn{3}{|l|}{ Policy \& Regulation } \\
\hline $\begin{array}{l}\text { Political targets: adherence to national and international } \\
\text { energy and climate targets }\end{array}$ & $\mathrm{H}$ & $\begin{array}{l}\text { Constraints reflecting European/national renewable energy } \\
\text { targets and } \mathrm{CO}_{2} \text { targets }\end{array}$ \\
\hline Local air pollution: importance in the national regulations & M & $\begin{array}{l}\text { Add externality cost and bound associated with PM, NOx, SO2 and } \\
\text { CO emissions }\end{array}$ \\
\hline $\begin{array}{l}\text { Taxes: parking fees, congestion pricing, road, tax exemption } \\
\text { on electric vehicles and bikes }\end{array}$ & M & $\begin{array}{l}\text { Introduce and adjust additional taxes/subsidies on specific vehicle } \\
\text { technologies }\end{array}$ \\
\hline
\end{tabular}




\begin{tabular}{|c|c|c|}
\hline Urbanisation: speed and diffusion of the trend & $\mathrm{M}$ & Use the trend to forecast the future energy and transport demand \\
\hline $\begin{array}{l}\text { New urbanisation: effect of urban sprawl on city centre and } \\
\text { outskirts }\end{array}$ & $\mathrm{L}$ & \\
\hline \multicolumn{3}{|l|}{ Behaviour } \\
\hline $\begin{array}{l}\text { Environmental awareness: level of diffusion among } \\
\text { consumers }\end{array}$ & $\mathrm{H}$ & $\begin{array}{l}\text { Constraint on the use of more efficient and sustainable } \\
\text { technologies }\end{array}$ \\
\hline $\begin{array}{l}\text { Frequency of business travel: impact on demand and mode } \\
\text { for long distance travel }\end{array}$ & M & Model as a change in long distance travel demand \\
\hline $\begin{array}{l}\text { Diffusion of co-driving, multi driver lanes shared with bus \& } \\
\text { taxi }\end{array}$ & M & Adjust the occupancy factor of private road vehicles \\
\hline Flexibility of work schedules & $\mathrm{L}$ & \\
\hline \multicolumn{3}{|l|}{ Technology } \\
\hline Level of adoption of electrical transport & $\mathrm{H}$ & $\begin{array}{l}\text { Constraint on minimum penetration of electric vehicles in the } \\
\text { technology mix }\end{array}$ \\
\hline $\begin{array}{l}\text { Autonomous cars: level of diffusion and net effects on } \\
\text { transport demand }\end{array}$ & M & $\begin{array}{l}\text { Introduce new passenger transport technology with different } \\
\text { yearly mileage and occupancy factor }\end{array}$ \\
\hline Technology availability & M & $\begin{array}{l}\text { Change year of introduction of vehicle and fuel technologies and } \\
\text { biofuel blending limits }\end{array}$ \\
\hline $\begin{array}{l}\text { Drone transport: level of diffusion and net effects on } \\
\text { transport demand }\end{array}$ & $\mathrm{L}$ & \\
\hline
\end{tabular}

In the translation step, the qualitative descriptions collected alongside each parameter name had to be interpreted and adjusted to the model framework (Trutnevyte et al., 2014). For example, accessibility of public transport is a broad term describing the interconnectedness of bus, metro and train modes, the frequency of their services, the vicinity of stations and the possibility of travelling at lower price with respect to private modes. Because the energy system model TIMES-DK specifies each technology according to monetary and time parameters, it is possible to express the accessibility of public transport by operating on either cost or time. Once again, to allow competition among modes and technologies, the model assigns an investment cost and an operation and maintenance cost, but not the ticket cost. Therefore, the remaining option is to model the accessibility of public transport by acting on the time parameter: whenever the scenario narrative envisions a high development for the key driving force Infrastructure, the travelling time associated to public transport modes is decreased to simulate a reduction in the waiting time.

Since all models are simplified constructions of reality, the translation process into model attributes inherently simplifies the breadth of the qualitative descriptions (Geels et al., 2016; Garb et al., 2008). For instance, the parameter diffusion of co-driving, multi driver lanes shared with bus \& taxi was identified as important to include in the modelled scenarios. However, during the translation phase the coverage of the parameter's meaning had to be reduced to limit the model complexity. The parameter has been rendered with the simpler car sharing, hereby adjusting the occupancy level of private road vehicles to reflect the changes in transport users' behaviour.

\subsection{Quantification of driving forces}

For each parameter to be included in the modelled scenarios, the quantification step involved literature review and data collection on trends and future projections, followed by assumptions drawn for the determination of the three development levels. Lastly, the definition of the final scenarios result from the combination of all the parameters levels in accordance with the state assigned to the embracing driving forces in the narratives. While, on the one hand, this generalized approach allows for a clear assignment of the development levels of each key driving force, on the other hand, specific information on the evolution of one or few parameters could be missed.

Table 5 reports the assumptions behind some of the quantified parameters, thereby showing an example of scenario definition for two scenarios developed by the scenario panel, "Last Minute Action 2050" and "No 
Leadership - Market Delivers". The purpose of the study is not the one of providing modelling results for a full range of energy and transport scenarios, but that of applying the case of the Danish transport system to illustrate the possible integration of qualitative narratives and quantitative modelling, through involvement of stakeholders. Therefore, we chose to perform the modelling in TIMES-DK only for the two scenarios created by the scenario panel during WS2, as these would generate greater interest and engagement among the stakeholder group, as well as increased relevance of the revision process (Section 4.6).

The parameter accessibility of public transport refers to the interconnectedness of public transport, which is reflected in the model TIMES-DK through adjustments in the waiting time experienced during short- and medium-distance journeys by bus and train (Section 4.3). Passenger travel data extracted from the Danish National transport model LTM (Rich et al., 2010) for the base year 2010, allowed to calculate that average waiting and walking time weight respectively $4 \%$ and $2 \%$ on the total travel time on public transport. Therefore, considering that the average non-in-vehicle time corresponds to $6 \%$ of the total, the high level includes a reduction of the total travelling time by $5 \%$; in the medium level, the total time is reduced by $3 \%$; in the low level, no changes are applied to the base version of the model.

As explained in Section 4.3, diffusion of co-driving, multi driver lanes shared with bus \& taxi is modelled by adjusting the occupancy factor of cars, as to represent the development of car sharing systems and the adoption of car-pooling. The current average occupancy factor for cars in Denmark equals 1.55 passenger/vehicle. The European Environment Agency (2010) provides the vehicle occupancy factors for different European countries between 2004 and 2008, where the maximum value for some Eastern European countries reached the value of 2 passenger/vehicle. However, there has been a decreasing trend for this factor over time. The most optimistic development for this parameter (i.e. high) has been therefore assumed equal to the maximum value reached on average in some European countries according to European and Danish statistics (notably Hungary, Slovenia and Sweden), corresponding to 2 passenger/vehicle. The low level equals the current value of 1.55 while the medium level takes a value in between, i.e. 1.78 passenger/vehicle.

For the driving force Policy and Regulation, the translation and quantification followed a simpler approach: the most relevant qualitative parameters have been translated into the main overarching energy and climate targets and policies with impact on the Danish transport sector. In the scenario definition, the single policy constraints are active or inactive according to the level of ambition set for the driving force Policy and Regulation. The first two targets Phase-out fossil fuels and Danish Climate Law are long-term visions of the Danish Parliament for the year 2050, respectively corresponding to independence from fossil fuels in all sectors of the economy, and reduction of greenhouse gas (GHG) emissions to $80 \%$ below 1990 levels by 2050, as a contribution of all sectors. The EU 2020 targets reflect the Renewable Energy Directive 2009/28/EC (EC, 2009), in which three main goals are set: a) reduction of GHG emissions from buildings, agriculture and transportation of $20 \%$ between 2005 and 2020 ; b) the fraction of renewable energy in the total energy consumption should be $30 \%$ in 2020 ; c) the fraction of RE in the transport sector should be $10 \%$ in 2020 . With respect to the EU 2030 targets, the general goal is a reduction of emissions from the EU as a whole of $40 \%$ between 1990 and 2030 (EC, 2016). In accordance with the target expressed in the Annex 1 of EC (2016), we considered for Denmark a 39\% reduction in GHG emissions in 2030 with respect to 2005 levels. Furthermore, we applied the specific constraint of reaching at least $27 \%$ RE in total energy consumption by 2030 to the Danish case. The last policy item, Min. 50\% wind powered electricity by 2020, represents a short-term target set by the Danish Parliament for the heat and power sector, yet with implications on the rest of the energy system, including the transport sector.

The driving force Macro Economy has been excluded from the quantification since changing its development level would influence the end-use sectors demands (including transport demand) and make the comparison across scenarios less straightforward. 
Table 5. Scenario definition for the two scenarios "No Leadership - Market Delivers" and "Last Minute Action 2050". The column Method contains a description of the data collection methodology, including the main source used for the quantification of the parameter. Colour legend: High level, Medium level, Low level.

\begin{tabular}{|c|c|c|c|c|c|}
\hline & \multicolumn{2}{|c|}{ No Leadership - Market Delivers } & \multicolumn{3}{|c|}{ Last Minute Action 2050} \\
\hline & Translation & Quantification & Translation & Quantification & Method \\
\hline \multicolumn{6}{|l|}{ Technology } \\
\hline $\begin{array}{l}\text { Adoption of } \\
\text { electrical transport }\end{array}$ & High penetration of EV & 200000 EV in 2030 & High penetration of EV & $200000 \mathrm{EV}$ in 2030 & $\begin{array}{l}\text { Literature review of targets } \\
\text { (International Energy Agency, } \\
\text { 2011) }\end{array}$ \\
\hline $\begin{array}{l}\text { Technology } \\
\text { availability }\end{array}$ & $\begin{array}{l}\text { Early year of } \\
\text { introduction of fuel } \\
\text { technologies (i.e. } \\
\text { blending limits for } \\
\text { biofuels) }\end{array}$ & $\begin{array}{l}\text { Min. blending for } \\
\text { bioethanol and biodiesel } \\
\text { in 2020: } 10 \% \text {, in } \\
2040: 30 \% \text {; Min } \\
\text { blending for } \\
\text { biokerosene in } 2050 \text { : } \\
40 \%\end{array}$ & $\begin{array}{l}\text { Early year of } \\
\text { introduction of fuel } \\
\text { technologies (i.e. } \\
\text { blending limits for } \\
\text { biofuels) }\end{array}$ & $\begin{array}{l}\text { Min. blending for } \\
\text { bioethanol and biodiesel } \\
\text { in 2020: } 10 \% \text {, in } \\
2040 \text { : } 30 \% \text {; Min } \\
\text { blending for } \\
\text { biokerosene in 2050: } \\
40 \%\end{array}$ & $\begin{array}{l}\text { Literature review of minimum } \\
\text { legal requirements and } \\
\text { maximum technical blending }\end{array}$ \\
\hline $\begin{array}{l}\text { Cost and variety of } \\
\text { vehicles }\end{array}$ & $\begin{array}{l}\text { Decreased cost of } \\
\text { vehicles }\end{array}$ & $\begin{array}{l}\text { All cars, vans, trucks and } \\
\text { busses follow } 2035 \text { and } \\
2050 \text { decrease } \\
\text { projections }\end{array}$ & $\begin{array}{l}\text { Decreased cost of } \\
\text { vehicles }\end{array}$ & $\begin{array}{l}\text { All cars, vans, trucks and } \\
\text { busses follow } 2035 \text { and } \\
2050 \text { decrease } \\
\text { projections }\end{array}$ & $\begin{array}{l}\text { Literature review of vehicle } \\
\text { costs projections } \\
\text { (Dansk Energi, 2015) }\end{array}$ \\
\hline Electric bikes & $\begin{array}{l}\text { High share of electric } \\
\text { bikes on total share of } \\
\text { bikes }\end{array}$ & $\begin{array}{l}3 \% \text { in } 2025 \text { and } 5 \% \text { in } \\
2050\end{array}$ & $\begin{array}{l}\text { High share of electric } \\
\text { bikes on total share of } \\
\text { bikes }\end{array}$ & $\begin{array}{l}3 \% \text { in } 2025 \text { and } 5 \% \text { in } \\
2050\end{array}$ & $\begin{array}{l}\text { Data analysis on mode shares } \\
\text { with TIMES-DK } \\
\text { Own assumption }\end{array}$ \\
\hline Hydrogen \& gas & $\begin{array}{l}\text { High share of natural } \\
\text { gas in passenger and } \\
\text { freight transport }\end{array}$ & $\begin{array}{l}\text { Development of gas } \\
\text { filling stations } \\
\text { infrastructure to serve } \\
50000 \text { vehicles in } 2030\end{array}$ & $\begin{array}{l}\text { High share of natural } \\
\text { gas in passenger and } \\
\text { freight transport }\end{array}$ & $\begin{array}{l}\text { Development of gas } \\
\text { filling stations } \\
\text { infrastructure to serve } \\
50000 \text { vehicles in } 2030 \\
\end{array}$ & $\begin{array}{l}\text { Data analysis on gas vehicles } \\
\text { (Statistics Denmark) } \\
\text { Own assumption }\end{array}$ \\
\hline Biofuels potential & $\begin{array}{l}\text { High availability of } \\
\text { biomass }\end{array}$ & $\begin{array}{l}\text { Total national potential: } \\
186 \mathrm{PJ}\end{array}$ & $\begin{array}{l}\text { High availability of } \\
\text { biomass }\end{array}$ & $\begin{array}{l}\text { Total national potential: } \\
186 \mathrm{PJ}\end{array}$ & $\begin{array}{l}\text { Literature review on domestic } \\
\text { biomass potentials } \\
\text { (Danish Energy Agency, } \\
\text { 2014a) } \\
\text { (Astrup et al., 2011) }\end{array}$ \\
\hline \multicolumn{6}{|l|}{ Infrastructure } \\
\hline $\begin{array}{l}\text { Bicycling paths - go } \\
\text { electric bikes }\end{array}$ & $\begin{array}{l}\text { High investments in bike } \\
\text { path infrastructure }\end{array}$ & $\begin{array}{l}\text { Current saturation } \\
\text { factor of bike paths = } \\
80 \%\end{array}$ & $\begin{array}{l}\text { Medium investments in } \\
\text { bike path infrastructure }\end{array}$ & $\begin{array}{l}\text { Current saturation } \\
\text { factor of bike paths = } \\
90 \%\end{array}$ & $\begin{array}{l}\text { Data analysis with TIMES-DK } \\
\text { Own assumption }\end{array}$ \\
\hline Faster trains & $\begin{array}{l}\text { Decreased travel time } \\
\text { for long distance } \\
\text { demands }\end{array}$ & $\begin{array}{l}\text { Average speed long } \\
\text { distance trains = } 111 \\
\mathrm{~km} / \text { hour }\end{array}$ & $\begin{array}{l}\text { Slight decrease in travel } \\
\text { time for long distance } \\
\text { demands }\end{array}$ & $\begin{array}{l}\text { Average speed long } \\
\text { distance trains = } 102 \\
\mathrm{~km} / \text { hour }\end{array}$ & $\begin{array}{l}\text { Data analysis on train speed } \\
\text { with TU survey data } \\
\text { (Christiansen \& Skougaard, } \\
\text { 2015) }\end{array}$ \\
\hline $\begin{array}{l}\text { Accessibility of public } \\
\text { transport }\end{array}$ & Reduced waiting time & $\begin{array}{l}\text { Total travelling time in } \\
\text { public transport reduced } \\
\text { by } 5 \%\end{array}$ & $\begin{array}{l}\text { Slight reduction in } \\
\text { waiting time }\end{array}$ & $\begin{array}{l}\text { Total travelling time in } \\
\text { public transport reduced } \\
\text { by } 3 \%\end{array}$ & $\begin{array}{l}\text { Data analysis on travelling } \\
\text { dimes with TU survey data } \\
\text { (Christiansen \& Skougaard, } \\
\text { 2015) }\end{array}$ \\
\hline EV Charging stations & $\begin{array}{l}\text { High development of EV } \\
\text { charging infrastructure }\end{array}$ & $\begin{array}{l}\text { Increase EV chargers to } \\
1 \text { every } 10 \text { cars in } 2030\end{array}$ & $\begin{array}{l}\text { Medium development } \\
\text { of EV charging } \\
\text { infrastructure }\end{array}$ & $\begin{array}{l}\text { Increase EV chargers to } \\
1 \text { every } 15 \text { cars in } 2030\end{array}$ & $\begin{array}{l}\text { Literature review } \\
\text { (European Union, 2014) }\end{array}$ \\
\hline \multicolumn{6}{|l|}{ Behaviour } \\
\hline $\begin{array}{l}\text { Demand for } \\
\text { international tourism }\end{array}$ & $\begin{array}{l}\text { Lower international air } \\
\text { transport demand }\end{array}$ & Reduced by $10 \%$ in 2050 & $\begin{array}{l}\text { Unchanged } \\
\text { international air } \\
\text { transport demand }\end{array}$ & $\begin{array}{l}\text { Denmark Statistics } \\
\text { projections }\end{array}$ & $\begin{array}{l}\text { Data analysis with TIMES-DK } \\
\text { Own assumptions }\end{array}$ \\
\hline $\begin{array}{l}\text { Frequency of } \\
\text { business travel (long } \\
\text { distance)/virtual } \\
\text { presence } \\
\end{array}$ & $\begin{array}{l}\text { Reduced long distance } \\
\text { travel demand }\end{array}$ & Reduced by 5\% in 2050 & $\begin{array}{l}\text { Medium reduction in } \\
\text { long distance travel } \\
\text { demand }\end{array}$ & Reduced by 3\% in 2050 & $\begin{array}{l}\text { Data analysis on business } \\
\text { commuting trips with TU } \\
\text { survey data (Christiansen \& } \\
\text { Skougaard, 2015) }\end{array}$ \\
\hline $\begin{array}{l}\text { Sharing (co-driving, } \\
\text { car sharing) }\end{array}$ & $\begin{array}{l}\text { High occupancy factor } \\
\text { for cars }\end{array}$ & $\begin{array}{l}\text { Passengers/car in } 2050 \\
=2\end{array}$ & $\begin{array}{l}\text { Above average } \\
\text { occupancy factor for } \\
\text { cars }\end{array}$ & $\begin{array}{l}\text { Passengers/car in } 2050 \\
=1.78\end{array}$ & $\begin{array}{l}\text { Literature review on cars } \\
\text { occupancy factors } \\
\text { (European Environment } \\
\text { Agency, 2010) }\end{array}$ \\
\hline \multicolumn{6}{|l|}{ Demography } \\
\hline $\begin{array}{l}\text { Effect of } \\
\text { urbanization }\end{array}$ & $\begin{array}{l}\text { Lower than projected } \\
\text { level of urbanization } \\
\text { (Status quo localization) }\end{array}$ & $\begin{array}{l}0.8 \% \text { higher road } \\
\text { transport demand in } \\
2050\end{array}$ & $\begin{array}{l}\text { Projected level of } \\
\text { urbanization (Statistics } \\
\text { Denmark) }\end{array}$ & $\begin{array}{l}\text { Denmark Statistics } \\
\text { projections for road } \\
\text { transport demand }\end{array}$ & $\begin{array}{l}\text { Data analysis with LTM model } \\
\text { (Brems, 2014) }\end{array}$ \\
\hline
\end{tabular}




\begin{tabular}{|c|c|c|c|c|c|}
\hline \multicolumn{6}{|l|}{ Policy \& Regulation } \\
\hline $\begin{array}{l}\text { Phase-out fossil fuels } \\
\text { in } 2050\end{array}$ & Weak political action & Inactive policy & $\begin{array}{l}\text { Strong political action, } \\
\text { but not immediate }\end{array}$ & Active policy & $\begin{array}{l}\text { Literature review on energy } \\
\text { and climate targets } \\
\text { (Danish Energy Agency, 2015) }\end{array}$ \\
\hline $\begin{array}{l}\text { Danish Climate Law } \\
\text { (Low emission } \\
\text { society by 2050) }\end{array}$ & Weak political action & Inactive policy & $\begin{array}{l}\text { Strong political action, } \\
\text { but not immediate }\end{array}$ & Active policy & $\begin{array}{l}\text { Literature review on energy } \\
\text { and climate targets } \\
\text { (Danish Energy Agency, 2015) }\end{array}$ \\
\hline EU 2020 targets & $\begin{array}{l}\text { Adherence to EU } \\
\text { directive }\end{array}$ & Active policy & $\begin{array}{l}\text { Strong adherence to EU } \\
\text { directive }\end{array}$ & Active policy & $\begin{array}{l}\text { Literature review on energy } \\
\text { and climate targets } \\
\text { (European Commission, 2009) }\end{array}$ \\
\hline EU 2030 targets & Weak political action & Inactive policy & Strong political action & Active policy & $\begin{array}{l}\text { Literature review on energy } \\
\text { and climate targets } \\
\text { (European Commission, 2016) }\end{array}$ \\
\hline $\begin{array}{l}\text { Min. } 50 \% \text { wind } \\
\text { powered electricity } \\
\text { by } 2020\end{array}$ & $\begin{array}{l}\text { Target already reached, } \\
\text { to be maintained }\end{array}$ & Active policy & $\begin{array}{l}\text { Target already reached, } \\
\text { to be maintained }\end{array}$ & Active policy & $\begin{array}{l}\text { Literature review on energy } \\
\text { and climate targets } \\
\text { (International Renewable } \\
\text { Energy Agency, 2013) }\end{array}$ \\
\hline
\end{tabular}

\subsection{Model results}

The scenarios were modelled in the energy system model TIMES-DK (Section 3.2.4), as to validate and assess the elements described in the qualitative storylines within a quantitative modelling framework (McDowall, 2014). This phase involved the adjustments of all relevant parameters and the setting of constraints according to the scenario definition, as in Table 5.

Within passenger transport, car remains the most used mode in both scenarios in all modelled years, representing 67\% of the total fuel consumption (PJ) in 2010 (Figure 3). However, in the scenario "Last Minute Action 2050", from 2025 the fuel consumption in cars starts decreasing, reaching $37.8 \%$ of the total fuel consumption in 2050. The decrease stems from two major reasons: the use of more fuel-efficient private vehicles (i.e. EVs) and the substitution of part of the car demand with bus demand. The mode share of busses (in million passenger km) shifts from 6.3\% in 2010 to 13.3\% in 2050 while in the scenario "No Leadership Market Delivers" the share for bus transport in 2050 is lower, and equal to $9.5 \%$. The energy system model finds the cost- and time-optimal transport technology and mode mixes. In fact, within the passenger road modes, modal shares are endogenously calculated by the model based on technology costs (both investment and operation) and travelling times. As visible from Table 6, the input to the model for the road modes is the total passenger demand (million passenger-km), from which the model internally determines the modal split among car, bus, rail, bike and walk.

Therefore, under the energy and climate targets set in the scenario "Last Minute Action 2050", energyefficient technologies and modes are preferred. Moreover, travelling times for public transport are reduced because of high development level assigned to the parameter accessibility of public transport in both scenarios. 


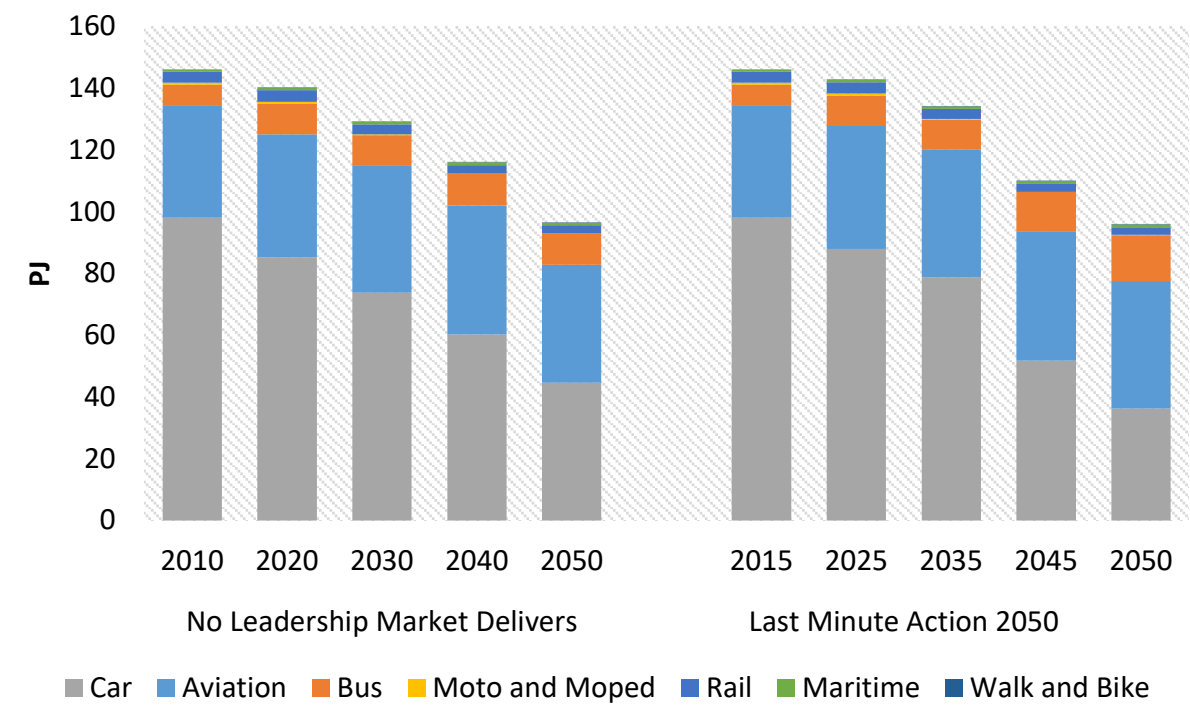

Figure 3. Fuel consumption in the passenger transport sector over time (PJ)

Table 6. Passenger transport demand (million passenger-km) in the two scenarios. Road modes include car, bus, rail, bike and walk.

\begin{tabular}{|c|c|c|c|c|c|c|c|c|c|}
\hline \multicolumn{10}{|c|}{ No Leadership - Market Delivers } \\
\hline & 2010 & 2015 & 2020 & 2025 & 2030 & 2035 & 2040 & 2045 & 2050 \\
\hline Inland modes & 70538 & 65694 & 65878 & 67425 & 68029 & 67985 & 68845 & 68940 & 69033 \\
\hline Air & 36860 & 38703 & 40546 & 41467 & 42388 & 43310 & 44231 & 42879 & 41526 \\
\hline Sea & 1666 & 1749 & 1832 & 1874 & 1916 & 1957 & 1999 & 2041 & 2082 \\
\hline \multicolumn{10}{|c|}{ Last Minute Action 2050} \\
\hline & 2010 & 2015 & 2020 & 2025 & 2030 & 2035 & 2040 & 2045 & 2050 \\
\hline Inland modes & 70538 & 65694 & 65894 & 67548 & 68062 & 67694 & 65608 & 64409 & 64284 \\
\hline Air & 36860 & 38703 & 40546 & 41467 & 42388 & 43310 & 44231 & 45153 & 46074 \\
\hline Sea & 1666 & 1749 & 1832 & 1874 & 1916 & 1957 & 1999 & 2041 & 2082 \\
\hline
\end{tabular}

Regarding freight transport, final demands (million ton-km) are assumed the same in both scenarios (Table 7). However, because of the late policies active in the scenario "Last Minute Action 2050", we witness a lower fuel consumption from vans and trucks in 2050 with respect to the scenario "No Leadership - Market Delivers" (Figure 4). The reason is ascribed to the selection of more fuel-efficient vehicles in 2050, namely electric vans and biodiesel trucks. 


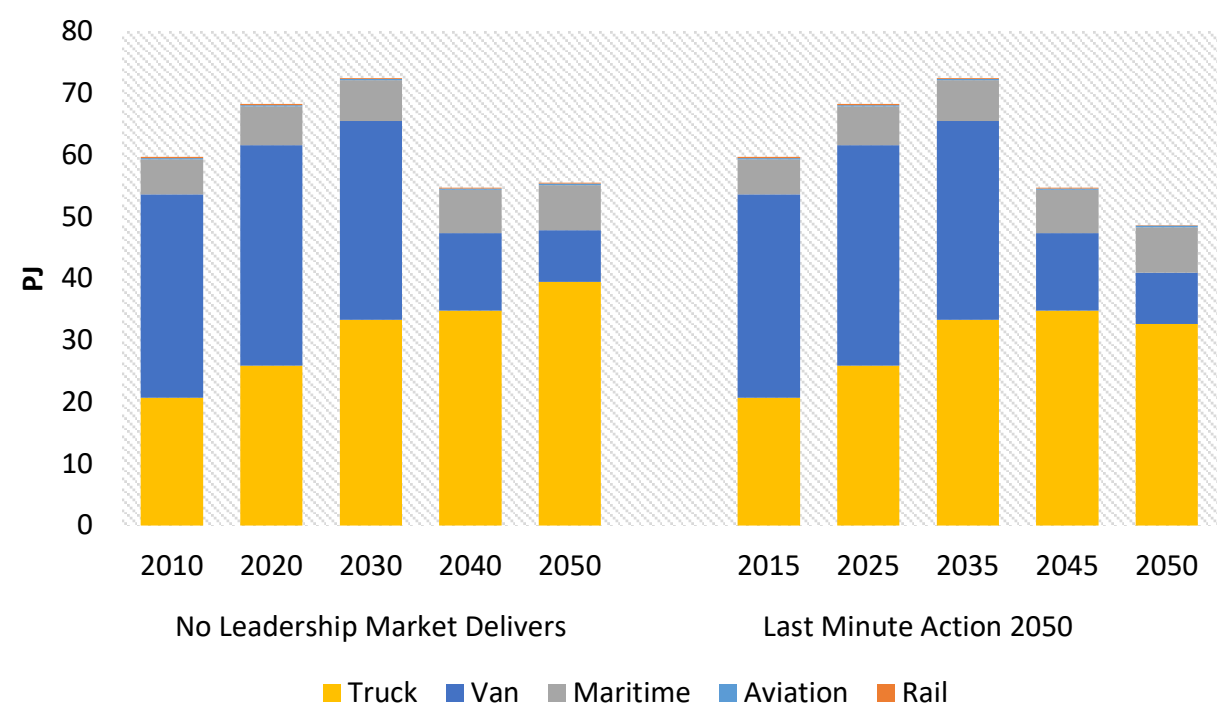

Figure 4. Fuel consumption in the freight transport sector over time (PJ)

Table 7. Freight transport demand (million ton-km), applying to both scenarios.

\begin{tabular}{llllllllll}
\hline & $\mathbf{2 0 1 0}$ & $\mathbf{2 0 1 5}$ & $\mathbf{2 0 2 0}$ & $\mathbf{2 0 2 5}$ & $\mathbf{2 0 3 0}$ & $\mathbf{2 0 3 5}$ & $\mathbf{2 0 4 0}$ & $\mathbf{2 0 4 5}$ & $\mathbf{2 0 5 0}$ \\
\hline Vans & 3670 & 3830 & 3996 & 4037 & 4078 & 4119 & 4161 & 4203 & 4246 \\
\hline Trucks & 19773 & 21660 & 23728 & 25260 & 26892 & 28628 & 30477 & 32445 & 34541 \\
\hline Rails & 374 & 393 & 411 & 421 & 430 & 439 & 449 & 458 & 468 \\
\hline Sea & 49010 & 51460 & 53911 & 55136 & 56361 & 57587 & 58812 & 60037 & 61262 \\
\hline Air & 632 & 663 & 695 & 711 & 727 & 742 & 758 & 774 & 790 \\
\hline
\end{tabular}

Figure 5 summarizes the total fuel consumption (PJ) across modes for the two scenarios. The visible shift in the fuels used in the "Last Minute Action 2050" scenario comes as a result of the targets to be reached by 2050, i.e. the Phase-out fossil fuels and the Danish Climate Law, corresponding to carbon neutrality in all modelled sectors of the system (industry, transport, residential, heat and power). The fossil fuels are thus replaced by the corresponding biomass-based liquid and gaseous fuels options, and by electricity. Gasoline is substituted by bio-ethanol and diesel by biodiesel in light and heavy-duty vehicles; kerosene is abandoned for bio-kerosene in the aviation sector while natural gas is either blended or completely replaced by biomethane.

In the scenario "No Leadership - Market Delivers" instead, fossil fuels continue being utilized until the end of the time horizon, with natural gas dominating the shares (37\% of the total). However, also electricity is used in this scenario ( $18 \%$ against the higher $22 \%$ in "Last Minute Action 2050 "), because of the assumed projections on the penetration of the EVs and the reduced purchase cost of cars in both scenarios (Table 5). Even though the transition from fossil fuels to more sustainable options gradually takes place in the "Last Minute Action 2050" scenario, the final fuel mix in 2050 (resulting from the perfect foresight model optimization) is far from realistic, since it would assume a sudden change to happen in the years 2040-2050, which can only be triggered by very strict regulations.

In both scenarios, the decrease in the total fuel consumption is, once more, resulting from the greater use of fuel-efficient technologies, the assumed increase in car occupancy and the projected efficiency improvements of vehicle engines. 


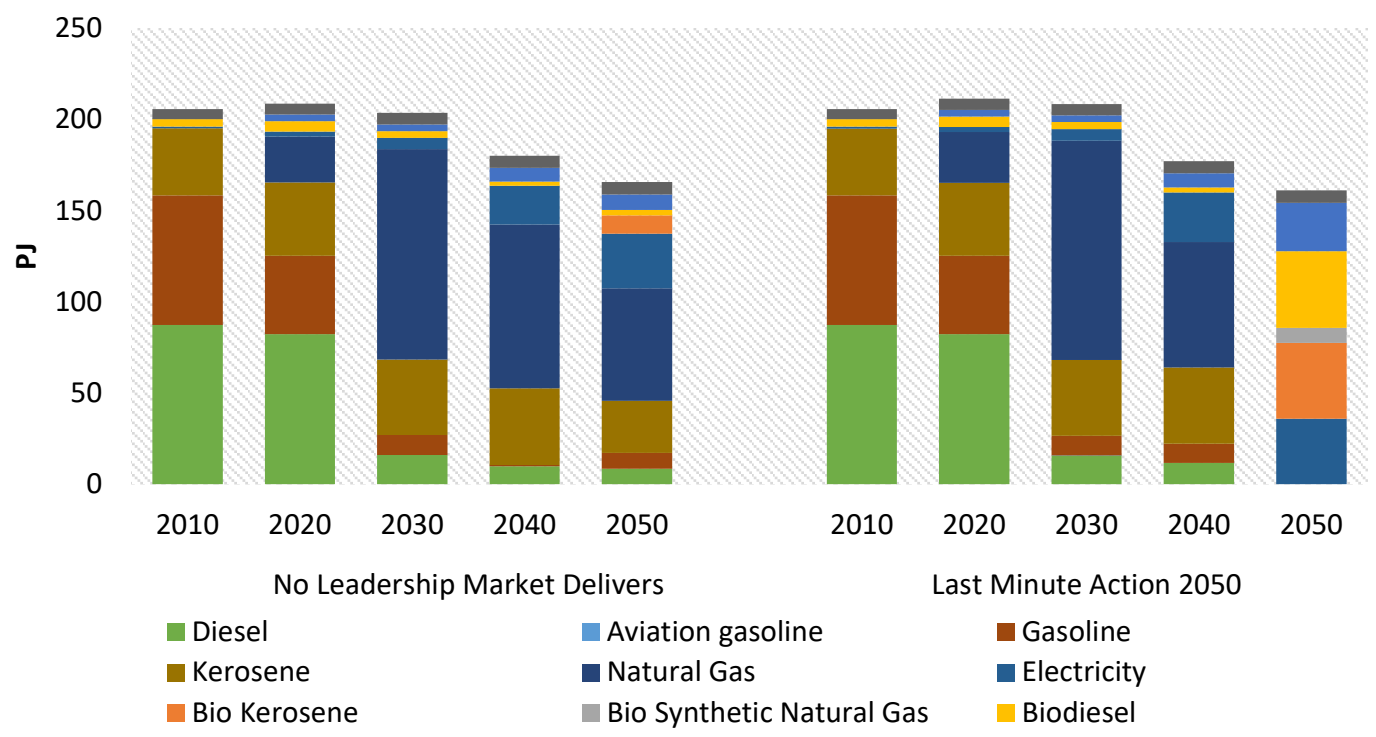

Figure 5. Total fuel consumption in the transport sector over time (PJ)

TIMES-DK associates $\mathrm{CO}_{2}$-equivalent emissions to the combustion of fuels used in all sectors. Therefore, the consumption of fossil fuels (e.g. gasoline, natural gas, and diesel) corresponds to the emission of GHG in the atmosphere, while biofuel production and use do not result in emissions of $\mathrm{CO}_{2}$, since it is assumed that biomass is carbon-neutral. This means that the biomass, used for biofuels production and for combustion in the heat and power sector, is harvested locally and in a sustainable manner; the biomass cycles of cultivationharvest-conversion-decade-regeneration are balanced, hence without drastic alterations to the exchanges between the biosphere and the atmosphere. A restriction is thus imposed in both scenarios so that biomass can only be sourced domestically and cannot be imported from abroad.

Figure 6 illustrates the decreasing trend in $\mathrm{CO}_{2}$ emissions associated to the transport sector, following from the active policies constraining the use of fossil fuels. However, there are differences between the two scenarios. The reduction is sharper in the scenario "Last Minute Action 2050", especially in the last period analysed. Moreover, while road, rail and air transport gradually reduce their impact on the environment, the navigation sector is not constrained and continues producing emissions in both scenarios.

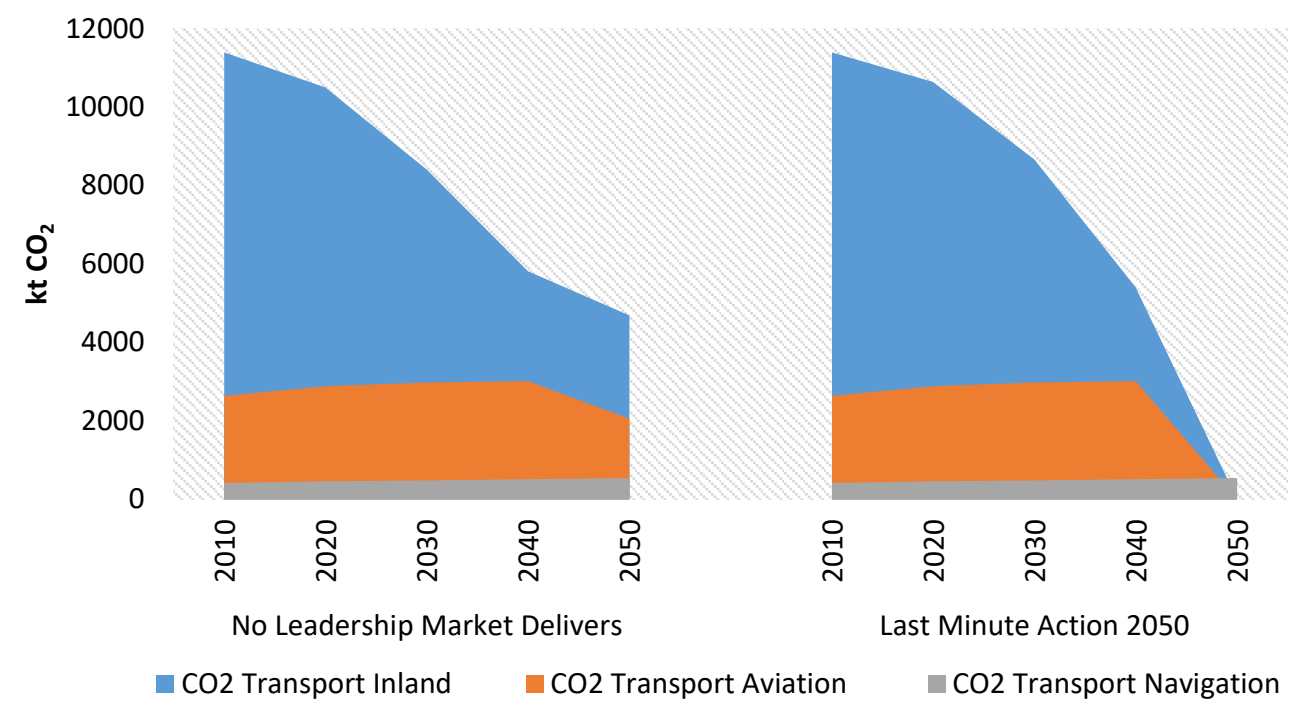

Figure 6. $\mathrm{CO}_{2}$ emissions in the transport sector over time ( $\left.k t\right)$ 


\subsection{Revision of modelled scenarios}

Among the seven stakeholders that participated in the feedback sessions, three of them highlighted the importance of modelling the registration tax paid when purchasing vehicles, which is currently based on the vehicle's weight and investment cost. The registration tax, together with fuel taxes, can indeed strongly affect consumers' purchase decisions and change the final picture on the vehicles used in the private passenger transport.

Furthermore, seen the conservative phasing-in of EVs in both scenarios, one expert recommended considering the cheaper option of "home charging", since charging patterns show that EV users charge their vehicles mostly at home (or at work), for $90 \%$ of the charging.

Among game changers not to be disregarded considering the foreseen impact on the transport sector, three stakeholders mentioned autonomous vehicles: their effect on mobility could correspond in an increase in the total road transport demand, because of the possibility of longer driving distances. The fuel used gives an additional layer of uncertainty.

The divergence between some of the parameters included in the quantitative framework and those highlighted as important during the follow-up discussion with stakeholders stems from the difficulty of spotting and rendering priorities and messages, which were implicit in the qualitative storylines.

For instance, with respect to the fuels used in the private passenger sector, two stakeholders considered the huge deployment of gas cars not realistic for the Danish case in the scenario "No Leadership - Market Delivers". Moreover, some others viewed the assumed penetration of EVs too pessimistic, considering the expected drop in batteries' prices. On the other hand, the use of first-generation biofuels (i.e. biodiesel) in transport was considered too large, especially taking into account the latest EU directives for a shift from first- to second-generation biofuels, along with the availability of biomass to produce the latter. Other specific comments regarded the drop in fuel use (PJ) over time, with reference to cars, considered dramatic with respect to e.g., fuel efficiency of vehicles, greater use of electricity and occupancy factor. The latter, according to two stakeholders, has been overestimated and its prospected increase is unrealistic, if considering that there has been a decreasing trend over time and the current average value in Denmark (2017) is around 1.35 passenger/vehicle.

In some cases the storylines and the model output did not align, because the narrative descriptions often implicitly assume some framework conditions, which cannot always be elicited in the quantitative scenarios (Fortes et al., 2015). For example, the scenario panel assigned the level high to the driving force Infrastructure, yet with reference to high development of roads, and not "green" infrastructure (e.g. bike paths, EV charging points), as it has been modelled. Furthermore, the scenario "No Leadership - Market Delivers" should resemble a situation in which the market pushes for a transition towards more sustainable mobility, through availability of cheap and efficient transport solutions. Instead, despite the high development assumed for the driving forces Technology and Infrastructure in this scenario, the system fails at reaching the envisioned RE targets. Thus the model does not fully reach the anticipated result that was envisioned in the storyline, which resulted in recognising the importance of detailing those parameters separately.

\section{Discussion}

\subsection{Insights on methodology}

Previous research has suggested that driving forces may function as a backbone in scenario planning processes (van't Klooster \& van Asselt, 2006). In the case of the Danish transport sector, they indeed were central to maintaining internal consistency, during the peer-reviewed and structured prioritization, translation and quantification steps of the qualitative storylines. By consistently directing our attention to 
the key drivers along the whole scenario development process, we are able to highlight the discrepancies that would unavoidably appear when multiple actor-groups are interpreting concepts. One example of this was the definition of the driving force Infrastructure, where stakeholders had conflicting ideas of its meaning, from bike lanes to road expansion.

The continuous focus on driving forces was useful firstly during a series of workshops where the scenario team and the scenario panel drafted narrative scenarios. In these workshops, the generated key driving forces served as guiding axes to create the scenario narratives. Here it was possible to discuss and evaluate the collection of driving forces and their interdependencies. After the quantitative scenarios were modelled in the energy system model TIMES-DK, an iterative process of scenario revision was initiated through the discussion with and involvement of members of the scenario panel. Also in this phase, the key driving forces were the leading dimensions used to communicate with stakeholders on the interpretation of the narratives and the differences between the implemented scenarios.

The use of multiple driving forces instead of a method with two axes allowed for a more coherent construction of scenarios: with multiple driving forces, the causal effects between any of those become more apparent. For example, when creating the narratives, setting a high level to the driver technology (e.g. fast technological development of electric vehicles) may or may not influence the development of infrastructure (e.g. availability of public charging stations) depending on where people will charge the cars. Thus, the use of driving forces can ensure the coverage of the most relevant parameters for each case.

The definition of key driving forces can arguably raise awareness (Hansen et al., 2016) and inspire mutual learning (Soria-Lara \& Banister, 2018; Baumann \& White, 2015) among both stakeholders and scientists, when identifying the relevant drivers and cause-effect relationships for the future transport system. Particularly, during the first brainstorming phase, the construction of influence chains allowed to find associations between the various parameters, for instance the links between demography, consumer behaviour and urban planning. More generally, the gap between the research team's expectations on the translation and modelling of driving forces, and the scenario panel's recognition of the model's strengths and limitations highlighted the importance of maintaining a dialogue between the two spheres of work (i.e. the scientists/modellers and the stakeholders/policy makers) to increase the relevance to transport policy (Banister \& Hickman, 2013).

A limitation of the process may lie in the strict adherence to the adopted scenario planning structure, giving less freedom on devising alternative scenario parameters and storylines with respect to those already defined. However, the iterative revision and calibration leaves room for adjustments both in the qualitative and quantitative scenarios. Moreover, the results of a socio-economic optimization tool could in some cases conflict with the everyday experience of people, as the latter face daily decisions on e.g. transport modes under a private-economic perspective. On the other hand, the use of a socio-economic model remains important, as it aids and informs policy makers on future options for system investment and possible consequences of policies.

\subsection{Insights on results}

The exercise of integrating qualitative storylines into a deterministic mathematical tool initiates a mutual exploration of two somewhat distinct worlds. In our case, the model selects the cost-optimal combination of vehicle and fuel technologies, given the described techno-economic assumptions. Yet, the results may differ from the real development of certain technologies, due to factors, which are not captured by the tool e.g., behaviour of consumers or lock-in effects in the fuel infrastructure. This gap between the least-cost solution provided by the model and the real future evolution of the transport sector becomes more evident from the discussion with the stakeholders, each one having different perspectives and expert judgement on the way the future of transport may unfold (Grunwald, 2011). Hence, it is critical to adopt an approach which is as 
inclusive and transparent as possible for the identification of transport futures (Hickman et al., 2012).

The greatest decoupling between the socio-economic optimal solution and the stakeholder's knowledge represented a valuable learning opportunity for the scientific work performed within, but also outside, the project: the inclusion of vehicle and fuel taxation allows to capture the reality of individuals faced with purchase decisions more closely than when running a pure socio-economic calculation (i.e. without tax and subsidies). As a result, taxation is being currently integrated in the scenario modelling work, as to portray current and future development of technological options in the energy and transport system. In this view, the combined approach has been proven beneficial for improving the model capabilities in representing the real dynamics of the system, by including more parameters and adjusting model structure (McDowall, 2014). Our approach revealed additional insights on the communication between the scientific project group and the involved stakeholders. Especially during the phase of revision of the modelled scenarios (Section 4.6), we recognize the importance of conveying the working philosophy, structure and limitations of the adopted modelling framework, as to align stakeholders' expectations on which part of reality can be sensibly captured when translating and quantifying the narratives. For instance, TIMES-DK holds the strength of representing the whole energy system and the dynamics between the sectors, yet it does not capture details on e.g. traffic flow and congestion, for which more disaggregated tools should be deployed. Therefore, a suite of models should support and complement the investigation of the more detailed research questions.

Moreover, the choice of modelling only the two scenarios developed by the scenario panel represents a limitation of the current study, in which a narrow set of futures was quantified and presented to the stakeholders. In contrast, given a more generous time schedule, the possibility of quantifying the full range of scenarios created during the workshops could certainly generate additional discussions and valuable feedback, enriching both the modelling capabilities and the scientific knowledge in the field. Finally, the challenges faced by the scientific team in the communication with stakeholders having different fields of expertise could be supported in the future by means of meta-models acting as interface between the academic, technical perspective and the actual transport policy and practice.

\section{Conclusion}

This study investigated the iterative and participatory application of driving forces in bridging qualitative and quantitative methods in the development of transport scenarios, presenting the case of the Danish transport sector. Stakeholders from the energy and transport field generated key driving forces and narratives of transport futures as a collective action. Subsequently, a structured prioritization, translation and quantification of the driving forces and qualitative storylines yielded the generation of quantitative scenarios in the energy system model TIMES-DK.

The contribution from this paper is twofold. Firstly, the study reveals methodological insights on the iterative and participatory use of driving forces in bridging qualitative and quantitative tools for scenario creation and analysis. In particular, a shared and consolidated generation and evaluation of driving forces can support a more robust and systematic translation, modelling and communication of scenarios with stakeholders. A further improvement of the process could envision a mid-way revision step, following the quantification of drivers performed by the scenario team. This extra phase would allow receiving feedback on the interpretation of the driving forces and narratives, as generated by the scenario panel, thus ensuring a better alignment between qualitative and quantitative scenarios. Moreover, the adopted foresight process including participatory and brainstorming elements can reveal drivers' interdependencies and critical aspects of the system. Although the participatory approach through stakeholder involvement increases the quality of scenario exercises (Reed, 2008), some limitations can be found in our study. First, twelve stakeholders participated in the second workshop (WS2), which sets a limit to the level of co-generated knowledge achieved in the workshop. Furthermore, seven stakeholders had the possibility of provide feedback on the 
modelling results in the revision step. Therefore, the low attendance level might have hindered the collection of valuable knowledge and feedback. Future work could include the application of our approach by engaging a larger number of stakeholders, thus requiring also a more generous timeframe.

Secondly, we contribute to learnings for the study of socio-technical transitions in the contextual case of the Danish transport sector. The adoption of driving forces allowed for an explicit and open discussion on inconsistencies between modelling results and experts' experience. As already highlighted, part of the inconsistencies may arise from the different perspectives: while TIMES-DK performs a long-term least-cost technical optimization of the energy and transport system, it may fail at capturing relevant behavioural changes and political/economic barriers. The introduction of reality factors could soften these discrepancies. Notably, the greatest decoupling between the socio-economic optimal solution and the stakeholder's knowledge has been the inclusion of vehicle and fuel taxation, which has since been considered in the modelling exercises, as a result of this study. Nevertheless, as some of the parameters and drivers lay outside the scope of the model, they could not be (directly) incorporated in the quantitative scenarios, thus possibly generating a narrower representation of the narratives developed by stakeholders, as reported in the revision phase. To overcome this limitation and provided a longer timeframe, a potential improvement could entail the utilization of support tools and analyses to assess the aspects overlooked in TIMES-DK.

Finally, the methodology employed in our study features general characteristics (e.g. creation of narratives in groups, evaluation and prioritization of drivers), making it applicable to other geographical contexts and knowledge fields.

\section{References}

Alcamo, J. (2008). The SAS Approach: Combining Qualitative and Quantitative Knowledge in Environmental Scenarios. Developments in Integrated Environmental Assessment, 2, 123-150. doi:10.1016/S1574101X(08)00406-7

Alizadeh, R., Lund, P. D., Beynaghi, A., Abolghasemi, M., \& Maknoon, R. (2016). An integrated scenario-based robust planning approach for foresight and strategic management with application to energy industry. Technological Forecasting and Social Change, 104, 162-171. doi:10.1016/j.techfore.2015.11.030

Andersen, P. D., Andersen, A. D., Jensen, P. A., \& Rasmussen, B. (2014). Sectoral innovation system foresight in practice: Nordic facilities management foresight. Futures, 61, 33-44. doi:10.1016/j.futures.2014.04.012

Andersen, P. D., \& Rasmussen, B. (2014). Introduction to foresight and foresight processes in practice: Note for the PhD course Strategic Foresight in Engineering. Department of Management Engineering, Technical University of Denmark.

Astrup, T., Tonini, D., Hamelin, L., Wenzel, H. (2011). Environmental assessment of renewable energy scenarios towards 2050. Coherent Energy and Environmental System Analysis. Background Report Part 5.

Balyk, O., Andersen, K.S., Dockweiler, S., Gargiulo, M., Karlsson, K., Naeraa, R., Petrović, S., Tattini, J., Telmansen, L., Venturini, G. (2019). TIMES-DK: technology-rich multi-sectoral optimisation model of the Danish energy system. Energy Strategy Reviews, 23, 13-22. doi:10.1016/j.esr.2018.11.003

Banister, D., \& Hickman, R. (2013). Transport futures: Thinking the unthinkable. Transport Policy, 29, 283293. doi:10.1016/j.tranpol.2012.07.005 
Baumann, C., \& White, S. (2015). Collaborative Stakeholder Dialogue: A Catalyst for Better Transport Policy Choices. International Journal of Sustainable Transportation, 9(1), 30-38.

doi:10.1080/15568318.2012.720357

Berkhout, F., Hertin, J., \& Jordan, A. (2002). Socio-economic futures in climate change impact assessment: using scenarios as 'learning machines'. Global Environmental Change-Human and Policy Dimensions, 12(2), 83-95. doi:10.1016/S0959-3780(02)00006-7

Blanco, H., \& Moudon, A. V. (2017). Havana's Transportation System: Future Scenarios. Transportation Research Procedia, 25, 4683-4695. doi:10.1016/j.trpro.2017.05.310

Brems, C. (2014). Landstrafikmodellen - Betydningen af centrale forudsætninger. Proceedings from the Annual Transport Conference at Aalborg University. (In Danish).

Bryant, B. P., \& Lempert, R. J. (2010). Thinking inside the box: A participatory, computer-assisted approach to scenario discovery. Technological Forecasting and Social Change, 77(1), 34-49. doi:10.1016/j.techfore.2009.08.002

Cherp, A., Vinichenko, V., Jewell, J., Brutschin, E., \& Sovacool, B. (2018). Integrating techno-economic, socio-technical and political perspectives on national energy transitions: A meta-theoretical framework. Energy Research and Social Science, 37, 175-190. doi:10.1016/j.erss.2017.09.015

Christiansen, H. \& Skougaard, B. (2015). Documentation of the Danish National Travel Survey. DTU Transport, Data- and Modelcenter.

Dansk Energi (2015). Fremtidig vejtransport, Analyse nr. 18 - 2015. (In Danish).

Dansk Energi (2013). Fossilfri Vejtransport 2050, Analyse nr. 10 - 2013. (In Danish).

Danish Energy Agency (2015). Denmark's Energy and Climate Outlook 2015.

Danish Energy Agency (2014a). Analyse af bioenergi i Danmark. (In Danish).

Danish Energy Agency (2014b). Energiscenarier frem mod 2020, 2035 og 2050. (In Danish).

EA Energy Analyses (2015). Grøn Roadmap. Scenarier og virkemidler til omstilling af Transportsektorens energiforbrug. (In Danish).

EA Energy Analyses (2008). Danish Greenhouse Gas Reduction Scenarios for 2020 and 2050.

European Commission (2016). Proposal for a REGULATION OF THE EUROPEAN PARLIAMENT AND OF THE COUNCIL on binding annual greenhouse gas emission reductions by Member States from 2021 to 2030 for a resilient Energy Union and to meet commitments under the Paris Agreement and amending Regulation No 525/2013 of the European Parliament and the Council on a mechanism for monitoring and reporting greenhouse gas emissions and other information relevant to climate change.

European Commission (2011). Energy roadmap 2050. COM(2011) 885 final of 15 December 2011.

European Commission (2009). Directive 2009/28/EC of the European Parliament and of the Council of 23 April 2009 on the promotion of the use of energy from renewable sources and amending and subsequently repealing Directives 2001/77/EC and 2003/30/EC.

European Commission (2008). Joint Research Centre. Backcasting approach for sustainable mobility. 
European Community (2004). Foresight for Transport: A foresight exercise to help forward thinking in transport and sectoral integration.

European Environment Agency (2010). Occupancy rates of passenger vehicles. Retrieved on July 2017 from: http://www.eea.europa.eu/data-and-maps/indicators/occupancy-rates-of-passenger-vehicles/occupancyrates-of-passenger-vehicles

European Environment Agency (2007). Land-use scenarios for Europe: qualitative and quantitative analysis on a European scale. https://doi.org/ISSN 1725-2237

European Road Transport Research Advisory Council (2009). ERTRAC - Road Transport Scenario 2030+. Road to Implementation.

European Union (2014). Directive 2014/94/EU of the European Parliament and of the Council of 22 October 2014 on the deployment of alternative fuels infrastructure. Official Journal of the European Union.

Fontela, E. (2000). Bridging the gap between scenarios and models. Foresight, 2(1), 10-14. doi:10.1108/14636680010802447

Fortes, P., Alvarenga, A., Seixas, J., \& Rodrigues, S. (2015). Long-term energy scenarios: Bridging the gap between socioeconomic storylines and energy modeling. Technological Forecasting and Social Change, 91, 161-178. doi:10.1016/j.techfore.2014.02.006

Garb, Y., Pulver, S., \& VanDeveer, S. D. (2008). Scenarios in society, society in scenarios: toward a social scientific analysis of storyline-driven environmental modeling. Environmental Research Letters, 3(4), 045015. doi:10.1088/1748-9326/3/4/045015

Geels, F. W., Berkhout, F., \& van Vuuren, D. P. (2016). Bridging analytical approaches for low-carbon transitions. Nature Climate Change, 6(6), 576-583. doi:10.1038/NCLIMATE2980

Grunwald, A. (2011). Energy futures: Diversity and the need for assessment. Futures, 43(8), 820-830. doi:10.1016/j.futures.2011.05.024

Hansen, M. S., Rasmussen, L. B., \& Jacobsen, P. (2016). Interactive Foresight Simulation. Technological Forecasting and Social Change, 103, 214-227. doi:10.1016/j.techfore.2015.10.011

Hickman, R., Saxena, S., Banister, D., \& Ashiru, O. (2012). Examining transport futures with scenario analysis and MCA. Transportation Research Part A-Policy and Practice, 46(3), 560-575. doi.org/10.1016/j.tra.2011.11.006

IDA - The Danish Society of Engineers (2009). The IDA Climate Plan 2050. Main report.

International Energy Agency (2017). $\mathrm{CO}_{2}$ emissions from fuel combustion. Highlights.

International Energy Agency (2016a). World Energy Outlook 2016.

International Energy Agency (2016b). Nordic Energy Technology Perspectives 2016. Cities, flexibility and pathways to carbon-neutrality.

International Energy Agency (2011). Technology Roadmap Electric and plug-in hybrid electric vehicles.

International Renewable Energy Agency (2013). 30 Years of Policies for Wind Energy: Lessons from Denmark. 
van't Klooster, S. A., \& van Asselt, B. A. (2006). Practising the scenario-axes technique. Futures, 38(1), 15-30. doi:10.1016/j.futures.2005.04.019

Kok, K., Baerlund, I., Floerke, M., Holman, I., Gramberger, M., Sendzimir, J., Stuch, B., Zellmer, K. (2015). European participatory scenario development: strengthening the link between stories and models. Climatic Change, 128(3-4), 187-200. doi:10.1007/s10584-014-1143-y

Kok, K., van Vliet, M., Baerlund, I., Dubel, A., \& Sendzimir, J. (2011). Combining participative backcasting and exploratory scenario development: Experiences from the SCENES project. Technological Forecasting and Social Change, 78(5), 835-851. doi:10.1016/j.techfore.2011.01.004

Kämäri, J., Alcamo, J., Bärlund, I., Duel, H., Farquharson, F., Flörke, M., Fry, M., Houghton-Carr, H., Kabat, P., Kaljonen, M., Kok, K., Meijer, K.S., Rekolainen, S., Sendzimir, J., Varjopuro, R., Villars, N. (2008). Envisioning the future of water in Europe - The SCENES project. E-Water. Official Publication of the European Water Association (EWA).

Leinonen, A., Wessberg, N., Tuominen, A. (2014). Nordic road transport and prospective value chains of renewable energy. TOP-NEST report.

Li, F. G. N., \& Pye, S. (2018). Uncertainty, politics, and technology: Expert perceptions on energy transitions in the United Kingdom. Energy Research and Social Science, 37, 122-132. doi:10.1016/j.erss.2017.10.003

Li, F. G. N., \& Strachan, N. (2016). Modelling energy transitions for climate targets under landscape and actor inertia. Environmental Innovation and Societal Transitions. doi:10.1016/j.eist.2016.08.002

Lund, H., et al. (2011). Coherent energy and environmental system analysis. Main report. Department of Development and Planning, Aalborg University.

Mathiesen, B. V., Lund, H., Connolly, D., Wenzel, H., Østergaard, P. A., Möller, B., Nielsen, S., Ridjan, I., Karnøe, P., Sperling, K., Hvelplund, F. (2015). Smart Energy Systems for coherent $100 \%$ renewable energy and transport solutions. Applied Energy, 145, 139-154. doi:10.1016/j.apenergy.2015.01.075

Mathy, S., Fink, M., \& Bibas, R. (2015). Rethinking the role of scenarios: Participatory scripting of low-carbon scenarios for France. Energy Policy, 77, 176-190. doi:10.1016/j.enpol.2014.11.002

McDowall, W. (2014). Exploring possible transition pathways for hydrogen energy: A hybrid approach using socio-technical scenarios and energy system modelling. Futures, 63, 1-14. doi:10.1016/j.futures.2014.07.004

Moallemi, E. A., \& Malekpour, S. (2018). A participatory exploratory modelling approach for long-term planning in energy transitions. Energy Research and Social Science, 35, 205-216. doi:10.1016/j.erss.2017.10.022

Mostashari, A. (2005). Stakeholder-assisted modeling and policy design for engineering systems. PhD Thesis. Massachusetts Institute of Technology.

Nakicenovic, N., Alcamo, J., Davis, G., de Vries, B., Fenhann, J., Gaffin, S., Gregory, K., Grübler, A., Jung, T.Y., Kram, T., Emilio la Rovere, E., Michaelis, L., Mori, S., Morita, T., Pepper, W., Pitcher, H., Price, L., Riahi, K., Roehrl, A., Rogner, H., Sankovski, A., Schlesinger, M., Shukla, P., Smith, S., Swart, R., van Rooyen, S., Victor, N., Dadi, Z. (2000). IPCC Special Reports: Special Report on Emissions Scenarios, Cambridge University Press, Cambridge, UK.

Nowack, M., Endrikat, J., \& Guenther, E. (2011). Review of Delphi-based scenario studies: Quality and design 
considerations. Technological Forecasting and Social Change, 78(9), 1603-1615. doi:10.1016/j.techfore.2011.03.006

O'Mahony, T. (2014). Integrated scenarios for energy: A methodology for the short term. Futures, 55, 41-57. doi:10.1016/j.futures.2013.11.002

O'Neill, B. C., Kriegler, E., Ebi, K. L., Kemp-Benedict, E., Riahi, K., Rothman, D.S., van Ruijven, B.J., van Vuuren, D.P., Birkmann, J., Kok, K., Levy, M., Solecki, W. (2017). The roads ahead: Narratives for shared socioeconomic pathways describing world futures in the 21st century. Global Environmental Change-Human and Policy Dimensions, 42, 169-180. doi:10.1016/j.gloenvcha.2015.01.004

Papachristos, G. (2014). Towards multi-system sociotechnical transitions: why simulate. Technology Analysis and Strategic Management, 26(9), 1037-1055. doi:10.1080/09537325.2014.944148

Pye, S., Li, F. G. N., Petersen, A., Broad, O., McDowall, W., Price, J., \& Usher, W. (2018). Assessing qualitative and quantitative dimensions of uncertainty in energy modelling for policy support in the United Kingdom. Energy Research and Social Science, 46, 332-344. doi:10.1016/j.erss.2018.07.028

Ramirez, R., \& Wilkinson, A. (2014). Rethinking the $2 \times 2$ scenario method: Grid or frames? Technological Forecasting and Social Change, 86, 254-264. doi:10.1016/j.techfore.2013.10.020

Reed, M. S. (2008). Stakeholder participation for environmental management: A literature review. Biological Conservation, 141(10), 2417-2431. doi:10.1016/j.biocon.2008.07.014

Rich, J., Nielsen O.A., Brems, C., Hansen, C.O. (2010). Overall design of the Danish National transport model. Conference proceedings to Annual Transport Conference 2010, Aalborg University.

Robertson, E., O'Grady, A., Barton, J., Galloway, S., Emmanuel-Yusuf, D., Leach, M., Hammond, G., Thomson, M., Foxon, T. (2017). Reconciling qualitative storylines and quantitative descriptions: An iterative approach. Technological Forecasting and Social Change, 118, 293-306. doi:10.1016/j.techfore.2017.02.030

Schuckmann, S. W., Gnatzy, T., Darkow, I.-L., \& von der Gracht, H. A. (2012). Analysis of factors influencing the development of transport infrastructure until the year 2030-A Delphi based scenario study. Technological Forecasting and Social Change, 79(8), 1373-1387. doi:10.1016/j.techfore.2012.05.008

Schwartz, P. (1996). The art of the long view. Planning for the Future in an Uncertain World (pp. 272). Currency Doubleday.

Schweizer, V. J., \& Kriegler, E. (2012). Improving environmental change research with systematic techniques for qualitative scenarios. Environmental Research Letters, 7(4), 044011. doi:10.1088/1748-9326/7/4/044011

Skinner, I., van Essen, H., Smokers, R., Hill, N. (2010). Towards the decarbonisation of EU's transport sector by 2050. Final report produced under the contract ENV.C.3/SER/2008/0053 between European Commission Directorate-General Environment and AEA Technology plc.

Soria-Lara, J. A., \& Banister, D. (2018). Evaluating the impacts of transport backcasting scenarios with multicriteria analysis. Transportation Research Part A: Policy and Practice, 110, 26-37. doi.org/10.1016/j.tra.2018.02.004

Sovacool, B. K., \& Blyth, P. L. (2015). Energy and environmental attitudes in the green state of Denmark: Implications for energy democracy, low carbon transitions, and energy literacy. Environmental Science and Policy, 54, 304-315. doi:10.1016/j.envsci.2015.07.011 
Sovacool, B. K. (2014). Energy studies need social science. Nature, 511(7511), 529-530. doi:10.1038/511529a

Tattini, J., Gargiulo, M., Karlsson, K. (2018). Reaching carbon neutral transport sector in Denmark - Evidence from the incorporation of modal shift into the TIMES energy system modeling framework. Energy Policy, 113, 571-583. doi.org/10.1016/j.enpol.2017.11.013

Teknologirådet (2012). Dansk Transport uden kul og olie - hvordan? (In Danish).

TransVisions (2009). TRANSvisions: Mobility scenarios toward a post-carbon society: Transvisions Task 2 Quantitative scenarios.

Trutnevyte, E., Barton, J., O'Grady, Á., Ogunkunle, D., Pudjianto, D., \& Robertson, E. (2014). Linking a storyline with multiple models: A cross-scale study of the UK power system transition. Technological Forecasting and Social Change, 89, 26-42. doi:10.1016/j.techfore.2014.08.018

Tuominen, A., Wessberg, N., Leinonen, A., Eerola, A. and Bolwig, S. (2014). Creating prospective value chains for renewable road transport energy sources up to 2050 in Nordic Countries. Transport Research Arena 2014, Paris.

Turnheim, B., Berkhout, F., Geels, F. W., Hof, A., McMeekin, A., Nykvist, B., \& van Vuuren, D. P. (2015). Evaluating sustainability transitions pathways: Bridging analytical approaches to address governance challenges. Global Environmental Change-Human and Policy Dimensions, 35, 239-253. doi:10.1016/j.gloenvcha.2015.08.010

Varho, V., \& Tapio, P. (2013). Combining the qualitative and quantitative with the $Q_{2}$ scenario technique The case of transport and climate. Technological Forecasting and Social Change, 80(4), 611-630. doi:10.1016/j.techfore.2012.09.004

Volkery, A., \& Ribeiro, T. (2009). Scenario planning in public policy: Understanding use, impacts and the role of institutional context factors. Technological Forecasting and Social Change, 76(9), 1198-1207. doi:10.1016/j.techfore.2009.07.009

Volkery, A., Ribeiro, T., Henrichs, T., \& Hoogeveen, Y. (2008). Your Vision or My Model? Lessons from Participatory Land Use Scenario Development on a European Scale. Systemic Practice and Action Research, 21(6), 459-477. doi:10.1007/s11213-008-9104-x

Wadud, Z., Mackenzie, D., \& Leiby, P. (2016). Help or hindrance ? The travel, energy and carbon impacts of highly automated vehicles. Transportation Research Part A, 86, 1-18. Doi:10.1016/j.tra.2015.12.001

Wilkinson, A., Kupers, R., \& Mangalagiu, D. (2013). How plausibility-based scenario practices are grappling with complexity to appreciate and address 21 st century challenges. Technological Forecasting and Social Change, 80(4), 699-710. doi:10.1016/j.techfore.2012.10.031

World Energy Council (2011). Global Transport Scenarios 2050.

World Energy Council (2016). World Energy Trilemma, 1-103. Retrieved on July 2017 from: http://www.worldenergy.org/publications/2016/world-energy-trilemma-2016-defining-measures-toaccelerate-the-energy-transition/ 